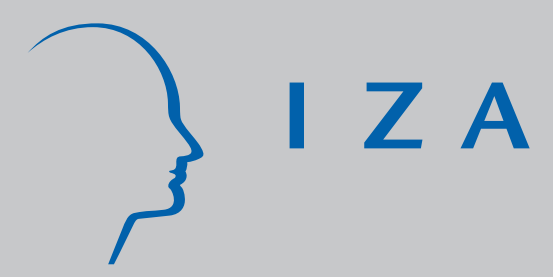

IZA DP No. 5868

And I Will Try to Fix You:

A Study of Heterogeneity in Job Satisfaction with Implications for Flexible Employment Contracts

Aekapol Chongvilaivan

Nattavudh Powdthavee

July 2011 


\title{
And I Will Try to Fix You: A Study of Heterogeneity in Job Satisfaction with Implications for Flexible Employment Contracts
}

\author{
Aekapol Chongvilaivan \\ Institute of Southeast Asian Studies \\ Nattavudh Powdthavee \\ Nanyang Technological University \\ and IZA
}

Discussion Paper No. 5868

July 2011

IZA

P.O. Box 7240

53072 Bonn

Germany

Phone: +49-228-3894-0

Fax: +49-228-3894-180

E-mail: iza@iza.org

\begin{abstract}
Any opinions expressed here are those of the author(s) and not those of IZA. Research published in this series may include views on policy, but the institute itself takes no institutional policy positions.

The Institute for the Study of Labor (IZA) in Bonn is a local and virtual international research center and a place of communication between science, politics and business. IZA is an independent nonprofit organization supported by Deutsche Post Foundation. The center is associated with the University of Bonn and offers a stimulating research environment through its international network, workshops and conferences, data service, project support, research visits and doctoral program. IZA engages in (i) original and internationally competitive research in all fields of labor economics, (ii) development of policy concepts, and (iii) dissemination of research results and concepts to the interested public.
\end{abstract}

IZA Discussion Papers often represent preliminary work and are circulated to encourage discussion. Citation of such a paper should account for its provisional character. A revised version may be available directly from the author. 
IZA Discussion Paper No. 5868

July 2011

\section{ABSTRACT}

\section{And I Will Try to Fix You: A Study of Heterogeneity in Job Satisfaction with Implications for Flexible Employment Contracts}

This paper is an empirical study of slope heterogeneity in job satisfaction. It provides evidence from the generalized ordered probit models that different job characteristics tend to have different distributional impacts on the overall job satisfaction. For instance, standard models tend to significantly underestimate the effects of monthly salary and hours worked at generating the "highly" satisfied workers, whilst lowering the incidence of the "very dissatisfied" workers. Although our results should be viewed as illustrative, we provide discussions of their potential implications for employers and they could help with the design of employment contracts.

JEL Classification: J53, D61

Keywords: job satisfaction, heterogeneity, employment contract, generalized ordered probit, salary, work-life balance

Corresponding author:

Nattavudh Powdthavee

Division of Economics

School of Humanities \& Social Sciences

Nanyang Technological University

14 Nanyang Drive

Singapore, 637332

E-mail: n.powdthavee@ntu.edu.sg 


\section{Introduction}

Research on job satisfaction as a determinant of objective economic behaviours has often neglected to report one particular result that, in the study of employer-employee relations, is potentially very valuable. This is, to quote the seminal work by Richard B. Freeman (1978, p. 135), whether "when [job] satisfaction is an independent variable, the set of dummies has an a priori ordering of effects with, for example, the third category having a larger effect than the second (relative to, say, the first) and the fourth a larger effect than the third". Most studies simply assume cardinality in the subjective data - i.e., that the difference between job-satisfaction scores of " 1 " and " 2 " is the same as that between " 3 " and " 4 " - and choose to report only the "average" predictive impact of job satisfaction on behaviours such as actual quits and intentions to quit (see, e.g., Freeman, 1978; Clark, 2001; Lévy-Garboua et al, 2007; Böckerman \& Ilmakunnas, 2009). To the best of our knowledge, very few studies have provided evidence that there is indeed a strict ordering effect of job satisfaction in equations where an objective economic behaviour is the dependent variable. For example, in a study by Shields and Wards (2001) on nurse retention in the National Health Service in England, those individuals who reported to be "very dissatisfied" with their job overall are $65 \%$ more likely to hold intentions to quit than those reporting to be "satisfied", with the probability of intending to quit decreasing monotonically with successively higher job satisfaction and with each being statistically significantly different from each other. ${ }^{2}$

Why should we care about the evidence of an ordering effect of job satisfaction? First, such evidence lends support to the idea that the measurement of job satisfaction is not significantly dominated by white noises (Bertrand \& Mullainathan, 2001), i.e., people really and categorically mean what they say. It also implies ordinal comparability across job-

\footnotetext{
${ }^{2}$ Those reporting to be "dissatisfied" and "neither satisfied or dissatisfied" with their job overall are respectively $53 \%$ and $32 \%$ more likely than the "very satisfied" group to hold intentions to quit.
} 
satisfaction responses, which, in other words, suggests that employees share a common opinion of what job satisfaction is and have a common understanding of how to translate inner feelings into a number scale that is, more or less, interpreted in the same way across all individuals (see Van Praag, 1991). Second, provided that each successive category on the job-satisfaction scale matters and statistically significantly differs, there is an additional incentive from the employer's point of view to utilize the findings on the determinants of job satisfaction and to create, perhaps at the lowest cost possible, a working environment that promotes their employees not only to be happier at work, but also to be (and confidentially reporting to be) among those highly "satisfied" with their job overall.

This seems possible in theory, but how feasible is it in practice, and how reliable are the results reported in the current literature? As it stands, there are at least two main and relatively unresolved problems associated with the findings on determinants of job satisfaction. The first is the well-known issue of causality (or how different job characteristics are causally linked with job satisfaction). The second, which forms the focus of this paper, is the issue of heterogeneity in job satisfaction.

Most empirical work on the determinants of job satisfaction uses either linear regression or single-index ordered probit and logit models. While the latter account for discreteness and ordering of job satisfaction, they impose an implicit cardinalization such that, for example, the trade-off ratios between income and work hours must be constant across the distribution of job satisfaction (see, e.g., Boes \& Winkelmann, 2006). For example, if an increase in salary of $2 \%$ is required on average to offset a fall in overall job satisfaction from an increase in the number of work hours by $1 \%$, then this trade-off ratio is assumed to remain constant across different parts of the job-satisfaction distribution. In other words, the standard ordered probit and logit models do not allow for the potential heterogeneous effects that income and work hours could have on the little-satisfied group as opposed to the highly 
satisfied group, thus discounting any possibilities of shortcuts to achieving the highest incidence of highly satisfied workers without having to make large sacrifices in other areas in return.

Recent econometric evidence, however, suggests that the implicit cardinalization of subjective well-being data may be too strong. For instance, Boes and Winkelmann (2010) have shown that income significantly reduces the incidence of people reporting low satisfaction with life overall but does not increase the incidence of high life satisfaction among men in Germany. Mentzakis (2011) also reports a considerable heterogeneity in the compensation variation for different types of health problems across different parts of the life-satisfaction distribution. Despite finding statistically insignificant average effect of grandparenthood on life satisfaction, Powdthavee (2011) shows that being a grandparent increases the probability of individuals reporting to be "very satisfied" with life overall. In short, there is increasing empirical evidence from studies that use less restrictive models that heterogeneity in subjective data matters in terms of what inferences we can draw from the estimation results.

Our paper follows the recent literature and explores what happens if the effects of many of the studied job characteristics such as incomes, work hours, and promotional opportunity are in fact different in different parts of the job-satisfaction distribution. What lessons can we learn from this, and what implications might this have on the employeremployee relations literature? To the best of our knowledge, empirical evidence on the heterogeneous effect of job characteristics on different parts of the job-satisfaction distribution is scarce, and discussions on the implications of such evidence are virtually nonexistent. For this reason, our paper aims to fill this gap in the literature. 
The remainder of this paper can be structured as follows. Section 2 reports our data set and presents descriptive statistics of our main variables. Section 3 develops our empirical strategy based on the generalized probit model and attempts to account for potential selection biases. Empirical results are discussed in Section 4. Section 5 concludes.

\section{Data}

The data set comes from Waves 1-18 of the British Household Panel Survey (BHPS). This is a multi-purpose study and a nationally representative sample of British households, containing over 15,000 adult individuals across UK. The survey has been conducted between September and Christmas of each year from 1991 to 2010, and is available for download from the UK Data Archive (www.data-archive.ac.uk).

From Wave 1 onward, individuals are asked to rate in confidence their levels of satisfaction with their jobs overall. Responses are given on a seven-point scale, ranging from 1 "very dissatisfied" to 7 "very satisfied". We focus our attention on individuals of working age (16-65) in full-time employment and working in the private sector, ${ }^{3}$ as well as the selfemployed, who also reported a level of job satisfaction in any given wave. This produces a nationally representative sample of 76,053 observations (15,674 individuals). Of those, 34,756 observations (7,696 individuals) are women, 41,297 (7,978 individuals) are men. Approximately $63 \%$ of the full sample are age 40 or under. The average salary is $£ 1,497.88$ per month, and the average number of hours worked is 34.19 per week. Most individuals are in a permanent job (97\%); around 34\% are in a job with a promotional opportunity; $17 \%$ are

\footnotetext{
${ }^{3}$ It is possible that the determinants of job satisfaction differ between public and private sector workers. However, since we do not aim to distinguish between the two, and for simplicity and relevance with the previous literature, we have decided to focus our attention in the current study only on those workers in the private sector.
} 
union members; and almost $25 \%$ have to make a (one way) journey of more than 30 minutes to work every day. Descriptive statistics of the main variables used in this paper's analysis can also be found in Table 1A in the Appendix.

Most people seem to be "highly" (to "very") satisfied with their job; approximately $44 \%$ of the British private and self-employed workers report a " 6 " on the seven-point jobsatisfaction scale, while $13 \%$ report to be "very satisfied" with their jobs overall (see the distribution of self-reported overall job satisfaction in Figure 1).

\section{Empirical strategy}

\subsection{Standard and generalized ordered probit}

The standard ordered probit model typically used in the estimation of job satisfaction can be formally written as follows:

$$
\operatorname{Pr}\left(J S_{i t}=j \mid X_{i t}\right)=\Phi\left(\omega_{j}-X_{i t} \theta\right)-\Phi\left(\omega_{j-1}-X_{i t} \theta\right) \quad j=1, \ldots, J-1
$$

where $i=1, \ldots, n$. The dependent variable $J S_{i} \in\{1, \ldots, J\}$ represents a self-reported level in response to an overall job-satisfaction question for individual $i=1, \ldots, n$ at time $t=1, \ldots, T$; $\omega_{j}$ denotes the threshold values, where $\omega_{1}, \ldots, \omega_{J+1} ; \theta$ is a vector of parameter estimates; and $\Phi(\bullet)$ denotes the cumulative density function (CDF) in which the variance, without loss of generality, is normalized to unity. The vector of explanatory variables, $X$, includes log of pay per month (in real terms), job tenure, job tenure squared, log of work hours per week, size of the workplace, a dummy representing whether the job is permanent or temporary, dummies for commuting time to work, union membership, opportunity for employment to work, and a dummy representing whether there is a pension scheme at the workplace, as well as the 
respondent's non-work variables, which are age, age squared, gender, health status, marital status, education, race dummies, occupational sector dummies, regional dummies, and wave dummies. Since it holds that $\omega_{1}=-\infty$ and $\omega_{J+1}=\infty$, then $\Phi\left(\omega_{1}-X_{i t} \theta\right)=0$; and $\Phi\left(\omega_{J+1}-X_{i t} \theta\right)=1$. As usual, the maximum-likelihood procedure is employed to estimate the vector of parameter estimates, $\theta$, along with $\omega_{j}$ in the job-satisfaction equation (1).

However, this conventional approach implicitly imposes a rather strong assumption that the job-satisfaction trade-off is homogenous across the distribution of outcomes, and, if the trade-off heterogeneity exists, may lead to biased and inconsistent estimates (Mentzakis, 2011; Boes \& Winkelmann, 2010). Since our key interest zeroes in on sensitivity with respect to the levels of job satisfaction, we opt for a more flexible framework of the generalized ordered probit estimation, where the effects of income and other characteristics across different levels of job satisfaction are unrestricted. The generalized setting can be written as:

$$
\begin{gathered}
J S_{i t}^{*}=X_{i t} \theta_{j}+u_{i t} \\
J S_{i t}=j \text { if } \omega_{i j-1}<J S_{i t}^{*} \leq \omega_{i j} \text { for } j=1, \ldots, J,
\end{gathered}
$$

where $J S_{i t}^{*}$ is the (unobserved) latent variable of job satisfaction associated with the (observed) response outcomes, $J S_{i t}$; and $\omega_{i j}=\omega_{j}+X_{i t} \lambda_{j}$. Heterogeneity enters the generalized ordered model in (2) and (3) in such a way that the threshold values, $\omega_{i j}$, are allowed to be a linear function of regressors, $X_{i t}$, making the vector of parameter estimates, $\theta_{j}$, and thus the marginal effects on satisfaction category-specific. The generalized ordered probit model can be depicted as:

$$
\operatorname{Pr}\left(J S_{i t}=j \mid X_{i t}\right)=\Phi\left(\omega_{j}-X_{i t} \theta_{j}\right)-\Phi\left(\omega_{j-1}-X_{i t} \theta_{j-1}\right)
$$


where $\theta_{j}=\theta-\lambda_{j}$. In addition, a well-defined likelihood requires that the order restriction is satisfied. That is, $\omega_{j}-X_{i t} \theta_{j} \leq \omega_{j+1}-X_{i t} \theta_{j+1}$, for all $i$ and $j$.

In the generalized ordered probit, the marginal probability effects of independent variables on job satisfaction are heterogeneous across different levels of satisfaction. In other words, the standard ordered probit model is nested in the generalized model (4) through the constraint $\theta_{1}=\ldots=\theta_{J}$ (Boes \& Winkelmann, 2004). Therefore, additional flexibility provided by relaxation of this restriction in the generalized model illuminates clearer insights into the satisfaction trade-off as the marginal probability effects run from the lowest to the highest job satisfaction. ${ }^{4}$ In panel data, equation (4) can be generalized further to allow for individual-specific random effects, $\mu_{i}$,

$$
\operatorname{Pr}\left(J S_{i t}=j \mid X_{i t}, \mu_{i}\right)=\Phi\left(\omega_{j}-X_{i t} \theta_{j}-\mu_{i}\right)-\Phi\left(\omega_{j-1}-X_{i t} \theta_{j-1}-\mu_{i}\right)
$$

where $\operatorname{COV}\left(\mu_{i}, X_{i t}\right)$ is assumed to be 0 . In cases where the assumption of no correlation between $\mu_{i}$ and $X_{i t}$ is violated, it is possible to follow the idea of Chamberlain (1980) under a Mundlak (1978) restriction to allow for possible correlation between $\mu_{i}$ and $X_{i t}$ as follows:

$$
\mu_{i}=\bar{X}_{i}+\alpha_{i}
$$

where $\bar{X}_{i}$ is the average of $X_{i t}$ over time (see also: Boes \& Winkelmann, 2010; Mentzakis, 2011).

\subsection{Accounting for selection bias}

\footnotetext{
${ }^{4}$ As Boes and Winkelmann (2004) highlight, the additional flexibility that the generalized ordered probit model offers does not come without costs. Now that the order restrictions have to be satisfied, computation of the generalized ordered probit estimates tends to be considerably tedious.
} 
We acknowledge that there may be some selection bias into full-time employment and selfemployment for those who are more satisfied at work (see, e.g., Heckman, 1979). In order to account for this, we compute an inverse Mills ratio using a selection variable that equals 1 if the individual is either in full-time employment or self-employed and 0 otherwise. The probit model for being employed is estimated on the entire work and non-work samples ( $\mathrm{N}=194,107$ observations) and includes all the socio-economic variables specified in $X$ as in equation (1), as well as a number of individual and household variables that help to determine the probability of employment but are assumed not to influence job satisfaction. These latter are variables that identify the selection model. Following Clark (1997), these include spouse's pay and spouse's hours worked and the variables' interaction with the respondent's gender, as well as numbers of children in various age groups, incomes of others in the household, and homeownership status. The estimates for the selection model are reported in Table 2A in the Appendix, and the inverse Mills ratio is included as an explanatory variable in all equations in the current study.

\section{Estimation results}

\subsection{Pooled cross section}

The standard ordered probit (OPROBIT) estimates and generalized ordered probit (GOPROBIT) estimates are presented in Table 1. The set of controls is as stated in equation (1). In the generalized model, six parameter vectors are estimated (where each vector contains coefficients for all the explanatory variables). All equations are estimated using STATA11.1 with robust standard errors and clustering by personal identification.

While we cannot interpret the estimated coefficients from either model directly, as the marginal effects of job characteristics on overall job satisfaction will be derived later, the comparisons of parameter estimates are useful for understanding our ensuing results. For 
example, if we were to focus our attention on the log of real-pay-per-month coefficients, we can see that they are twice or nearly twice as large for the parameters $\theta_{1}$ to $\theta_{4}$, and slightly larger for $\theta_{5}$, than the overall estimate in the standard model. The estimate becomes statistically insignificant for the parameter $\omega_{6}$. A similar pattern of decreasing point estimates as we move up the parameters from $\omega_{1}$ to $\omega_{6}$ is also observed for the estimated coefficients on log of hours worked per week and promotion opportunity. However, this does not apply to all variables; for instance, with respect to the workplace size of 500+ employees, most of the parameters are only slightly different from the point estimate obtained in the standard model. A Wald test on the generalized ordered probit model against the standard model also suggests that we can reject the null hypothesis of equal slope parameters $\left(\chi_{395}^{2}=3,924.19\right)$. In addition, the null hypothesis of equal coefficients can be rejected for 11 out of 16 jobcharacteristics variables (we can accept the null of equal slopes for the following variables: workplace pension; commute: 16-30 minutes; commute: 31-60 minutes; commute: 61-90 minutes; and self-employed). Hence, the results provide some of the preliminary evidence that job-characteristics parameters are heterogeneous with respect to the job-satisfaction distribution; in other words, there is slope heterogeneity in the job-satisfaction estimates. It is also worth noting that parameters of the inverse Mill's ratio are positive and statistically significant, thus implying that there is indeed a significant correlation between job satisfaction and selection into full-time employment (and self-employment).

\subsection{Random effects and Mundlak transformations models}

While cross-section models can provide us with suggestive results, they are considered less efficient compared to models that take into account the panel structure of the data set (and in some cases, cross-section models can be inconsistent if there is significant unobserved individual heterogeneity in self-reported job satisfaction). Since the BHPS is a longitudinal 
data set, it is possible to allow for the individual-specific random effects to be parameterized in the estimation of job satisfaction. Following Boes and Winkelmann (2010), Table 2 presents estimates taken from the random-effects generalized ordered probit model (REGOPROBIT), which allows for the individual differences in job satisfaction to be estimated alongside other parameters in the model.

We also provide in Table 3 estimates taken from the random-effects generalized ordered probit model with Mundlak transformations (RE-GOPROBIT-ML). While the REGOPROBIT model accounts for individual-specific random effects in panel data sets, its implicit assumption of no individual fixed effects, i.e., zero correlation between unobserved individual heterogeneity and the explanatory variables, is often rejected by the data. One could imagine, for example, that people who are born with persistent personality traits that make them happy with work may be more productive in the labour market and earn higher than usual incomes in the process. The effect of these unobserved characteristics may also vary across different parts of the job-satisfaction responses. To account for the possibility of the omitted time-invariant variables bias, a set of within-person averages - or the long-run effects - of the explanatory variables can be included as additional controls in the jobsatisfaction equation, that is, simply $\bar{X}_{i}$ of $X_{i t}$. According to Ferrer-i-Carbonell (2005), this so-called Mundlak transformations model yields similar results on the estimated coefficients of interest to other approaches that factor out individual fixed effects from the estimation. ${ }^{5}$

Comparing the RE-GOPROBIT estimates in Table 2, the RE-GOPROBIT-ML estimates in Table 3, and the GOPROBIT estimates in Table 1, we can see that, for many of the job-characteristics variables, there are little differences - in terms of size and statistical significance - in the point estimates across the three models. For example, the coefficients on

\footnotetext{
${ }^{5}$ For more examples of the Mundlak applications in subjective well-being data, see Mentzakis (2011) and Powdthavee and Van Den Berg (2011).
} 
the $\log$ of real pay per month for parameter $\omega_{1}$ are $0.216,0.264$, and 0.237 for GOPROBIT, RE-GOPROBIT, and RE-GOPROBIT-ML, respectively. Nevertheless, some of the differences can be seen for parameter $\omega_{6}$; e.g., the RE-GOPROBIT-ML coefficient on the $\log$ of real pay per month for parameter $\omega_{6}$ is 0.113 , which is similar to the 0.107 obtained by the standard ordered probit model. By contrast, the equivalent coefficients for GOPROBIT and RE-GOPROBIT for parameter $\omega_{6}$ are noticeably smaller at 0.008 and 0.031 , respectively.

\subsection{Marginal probability effects and trade-off ratios}

It is tempting to conclude based on the above results that whether or not the unobserved individual heterogeneity in the data set is accounted for ${ }^{6}$ makes only small differences to the point estimates but may result in large differences when one ignores the slope heterogeneity in job characteristics in job-satisfaction equations. However, we must first be able to interpret the estimated parameters directly and engage in formal comparisons of outcomes across models. According to Boes and Winkelmann (2010), there are two ways to interpret the standard and generalized ordered probit models. The first is the marginal probability effect (MPE) of each job attribute on job satisfaction, and the second involves the trade-off ratios between job characteristics. The former shows how marginal changes in one attribute affect the job-satisfaction distribution, while the latter method demonstrates how much one aspect of the job has to change in order to compensate for having to go without the other, e.g., how much additional income in $\%$ is required to compensate an average worker for a $1 \%$ increase

\footnotetext{
${ }^{6}$ This is important because, if there really are little differences in the point estimates between GOPROBIT, REGOPROBIT, and RE-GOPROBIT-ML, then researchers can simply estimate GOPROBIT on cross-section data without having to worry about potential unobserved heterogeneity bias contaminating their results.
} 
in the number of hours worked per week. This differs from the first method as the second implicitly responds to the heterogeneous effects of both job attributes simultaneously.

All of the MPEs are calculated from regression analysis in Tables 1-3. This produces fairly dense tables of statistical results. For ease of presentation, we choose to present only the estimated MPEs of the following job characteristics in Figures 2A-F: log of pay per month; log of hours worked per week; promotion opportunity; commute: 61-90 minutes; union membership; and pension scheme. ${ }^{7}$

Looking across the figures, we can see that there is considerable heterogeneity in the MPEs across job characteristics. For example, in Figure 2A, the MPE of log of pay per month on the probability of reporting a job-satisfaction score of "6" is approximately $(0.002 \times 100=) 2 \%$ when it is estimated using the OPROBIT. By contrast, the equivalent MPE is around 6\% when we allow for heterogeneity in overall job satisfaction (e.g., see the MPEs obtained from the remaining three generalized ordered probit models). With respect to the "very satisfied" group, the OPROBIT's MPE is, again, approximately $2 \%$. On the other hand, the MPEs from both GOPROBIT and RE-GOPROBIT are estimated to be slightly less than $1 \%$ and are statistically insignificantly different from 0 . Controlling for individual fixed effects, however, raises the MPE back to almost $2 \%$, which is statistically indistinguishable from the MPE produced by OPROBIT. This implies that a $1 \%$ increase in pay per month increases the probability of individuals reporting to be either " 6 " or " 7 " on the jobsatisfaction scale by $4 \%$ in the more restrictive model compared to around $7-8 \%$ in the less restrictive models. However, since the sum of all MPEs should equal 0 , we also see that a $1 \%$ increase in pay per month significantly reduces the probability of individuals reporting to be "neither satisfied or dissatisfied" with work (or "4") and the low-satisfaction (those reporting to be "1", "2", or "3") group.

\footnotetext{
${ }^{7}$ The rest of the MPEs can be supplied upon request.
} 
There is almost a reversal in the pattern of MPE in the hours worked per week; as illustrated in Figure 2A, a $1 \%$ increase in the number of hours worked per week reduces the probability of individuals reporting to be " 6 " on the job-satisfaction scale by $5 \%$ in the OPROBIT model, and around $9 \%$ in the generalized ordered probit models. Pooling the " $6 "$ and "7" job-satisfaction scales, a $1 \%$ increase in the number of hours worked lowers the probability of individuals reporting to be in these two categories by $11 \%$ in the OPROBIT model and $13-14 \%$ in the generalized models.

With respect to the MPE of promotional opportunity (Figure 2C), a move from 0 to 1 increases the probability of individuals reporting to be "very satisfied" with their jobs by approximately $6 \%$ in the OPROBIT model and slightly less than $4 \%$ in all three generalized models. The difference of around $2 \%$, which is statistically significant at conventional levels, implies that there is a possible overestimation of the impact of promotional opportunity on overall job satisfaction when the standard ordered probit is used to estimate the jobsatisfaction equation.

Figures 2D-F report the MPEs for the dummy variables representing commuting time: 61-90 minutes, union membership, and employer runs a pension scheme, respectively. Here, like the previous three job attributes, the slope heterogeneity in job satisfaction is also clear. For instance, the OPROBIT's MPE of commuting time of 61-90 minutes on individuals reporting to be "very satisfied" with their jobs is $-4 \%$ and is statistically significant at the 5\% level. However, the effect becomes statistically insignificantly different from 0 when we allow for both slope and individual heterogeneity in the job-satisfaction equation, i.e., the RE-GOPROBIT-ML model. The same can also be said for the union membership and pension scheme.

MPEs can also be presented in their normalized forms. Table 4 does this by dividing the estimated MPEs obtained in Figures $2 \mathrm{~A}-2 \mathrm{G}$ by the baseline job satisfaction distribution 
reported in Figure 1. For instance, a $1 \%$ increase in the monthly income raises the probability of individuals reporting to be "very satisfied" by $2.2 \%$ in the standard model. Consider that around $13.4 \%$ of people fall within this group, the normalized MPE of monthly income for the "very satisfied" group is therefore $=(2.2 / 13.4) \times 100=16.1 \%$. In other words, a $1 \%$ increase in the monthly income results in an increase in the proportion of people reporting to be "very satisfied" with their job from $13.4 \%$ to $15.6 \%$, which is equivalent to a $16.1 \%$ increase from the baseline level, holding other things constant.

MPEs can also be presented in their normalized forms. Table 4 does this by dividing the estimated MPEs obtained in Figures $2 \mathrm{~A}-\mathrm{G}$ by the baseline job-satisfaction distribution reported in Figure 1. For instance, a $1 \%$ increase in the monthly income raises the probability of individuals reporting to be "very satisfied" by $2.2 \%$ in the standard model. Considering that around $13.4 \%$ of people fall within this group, the normalized MPE of monthly income for the "very satisfied" group is therefore $=(2.2 / 13.4) \times 100=16.1 \%$. In other words, a $1 \%$ increase in the monthly income results in an increase in the proportion of people reporting to be "very satisfied" with their jobs from $13.4 \%$ to $15.6 \%$, which is equivalent to a $16.1 \%$ increase from the baseline level, holding other things constant.

By normalizing the MPEs, we now obtain evidence of slope heterogeneity that is much more visible than previously. For example, in the standard model, a $1 \%$ increase in the monthly income reduces the probability of people reporting " 1 " on the job-satisfaction scale from $1.7 \%$ to $1.4 \%$, i.e., a drop of $22 \%$ from the baseline level. The generalized models, however, produce a percentage change that is roughly twice as large (i.e., a drop of around $40-48 \%$ from $1.7 \%$ to $1 \%$ ). With respect to promotional opportunity, a move from 0 to 1 in the promotional-opportunity dummy corresponds to an approximately $40 \%$ increase from the baseline level in the proportion of people reporting to be "very satisfied" with their jobs in the standard ordered probit model. This figure decreases to around $27.1 \%$ in the RE- 
GOPROBIT-ML model. In short, slope heterogeneity matters in the estimation of job satisfaction.

The relationship between the MPEs of different job attributes at various parts of the overall job-satisfaction distribution can also be illustrated by trade-off ratios. For illustrative purposes, we present the following three scenarios of trade-off ratios in Figures $3 \mathrm{~A}-\mathrm{C}$ :

1) $\log$ of hours worked per week/log of pay per month,

2) promotional opportunity/log of hours worked per week, and

3) promotional opportunity/log of hours worked per week.

We normalize all MPEs to have positive values so that the trade-off ratios range from 0 to $\infty$. With this transformation, Figure 3A is equivalent to showing how much additional pay per month is required to compensate for a $1 \%$ increase in the number of hours worked per week; Figure 3B illustrates how much additional pay per month is equivalent to having a promotional opportunity at the workplace; and Figure 3C shows how much hours worked per week must be reduced to compensate for having no promotional opportunity at the workplace, holding the job-satisfaction distribution fixed.

In order to offset a $1 \%$ increase in the number of hours worked per week, pay per month must go up by approximately $2.6 \%$ in the OPROBIT model. By construction, the $2.6 \%$ trade-off ratio is the same for all levels of job satisfaction when the equation is estimated using the standard model. In the generalized models, the income change varies from $1.4 \%$ to $20.4 \%$ in the GOPROBIT; from $1.4 \%$ to $6.9 \%$ in the RE-GOPROBIT; and from $1.4 \%$ to $2.7 \%$ in the RE-GOPROBIT-ML. The latter result is particularly interesting as it implies almost zero differences in the estimated trade-offs between the standard model and the generalized model with Mundlak transformations. In other words, the ratio between the effects of income and hours worked is likely to be constant across the distribution of job satisfaction in equations where individual fixed effects are controlled for. One explanation for 
this is that, while income in the generalized model compared to the standard model affects much more those who reported " 6 " on the job-satisfaction scale, hours worked has the same greater effect for the same score on the same models.

We could also use the above principle to calculate the monetary value of a promotional opportunity in the workplace. According to Figure 3B, the standard model suggests that an additional pay of around $2.4 \%$ is equivalent to a move from 0 to 1 in the "promotional opportunity" dummy for all levels of job-satisfaction distribution. In the generalized models, the monetary values range from $1.3 \%$ to $24 \%$ in the GOPROBIT; from $1 \%$ to $7.6 \%$ in the RE-GOPROBIT; and from $1 \%$ to $2.1 \%$ in the RE-GOPROBIT-ML. The latter, again, is not so dissimilar to the estimated trade-off obtained in the standard model.

Finally, Figure 3C presents the calculated estimates of how much hours worked must be reduced - instead of a rise in pay - in order to "just" offset an average employee from working with no promotional opportunity. We can see that, with the standard model, hours worked must be reduced by approximately $0.9 \%$ in order to compensate for having no promotional opportunity at the workplace. The equivalent figure ranges from $0.6 \%$ to $1.2 \%$ in the GOPROBIT; from $0.6 \%$ to $1.1 \%$ in the RE-GOPROBIT; and from $0.5 \%$ to $1.1 \%$ in the RE-GOPROBIT-ML.

\section{Conclusions}

This paper follows Boes and Winkelmann (2010) and uses data from the BHPS (Waves 118) to study the potential implications of slope heterogeneity in the job-satisfaction distribution on employer-employee relations. By allowing the correlations between job characteristics and job satisfaction to vary flexibly across the job-satisfaction scale, we are able to show that moderate-to-considerable slope heterogeneity exists among the studied job attributes - namely monthly salary, hours worked per week, promotional opportunity, time 
spent commuting to work, union membership, and jobs that include a pension scheme. For instance, $\log$ of monthly salary has a higher (absolute) marginal effect on raising the probability of people reporting to be "highly satisfied" (i.e., reporting " 6 " or "7" on the jobsatisfaction scale) in the generalized model (7-8\%) than in the standard model (4\%); while a $1 \%$ decrease in the hours worked per week has a relatively higher impact on reducing the probability of people reporting to be "highly satisfied" in the generalized model (13-14\%) than in the standard model $(11 \%)$.

Faced with a relatively inflexible budget in which wages may be fixed in the shortrun, our results from the generalized ordered probit models suggest that more efficient ways of generating either "highly" or "very" satisfied workers, without placing too much strain on the available resources, may by and large exist. An employment package that offers a better work-life balance or options for flexible working conditions, all other things being constant, appears to be the most efficient way of increasing the incidence of highly satisfied workers and lowering the incidence of very dissatisfied workers. In the long-run, where wages are fully adjustable, employees may be offered options in which they could trade a fraction of their wage increases for more flexible working hours (or other perks) based on the trade-off parameters required to produce the "highly" or "very" satisfied workers in the generalized models.

We began by noting a potentially significant ordinal effect of job satisfaction on objective economic behaviours such as quits and performances, and that there may be incentives for employers to try and maximise the incidence of "highly" or "very" satisfied workers. The above results seem to suggest that, when slope heterogeneity in job satisfaction has been taken into account in the analysis, more efficient ways to achieve this may exist. Although our results should be viewed as illustrative (for one, the issue of income endogeneity is not satisfactorily dealt with in this paper), they call for more generalized 
models of ordered probit (or logit) to be incorporated in the analysis of job satisfaction in the future. 


\section{References}

Bertrand, Marianne, Sendhil Mullainathan. 2001. Do people mean what they say? Implications for subjective survey data. American Economic Review, 91, 67-72.

Böckerman, Petri, and Pekka Ilmakunnas. 2009. Job disamenities, job satisfaction, quit intentions, and actual separations: putting the pieces together. Industrial Relations, 48(1), 7396.

Boes, Stefan, and Rainer Winkelmann. 2004. Income and happiness: new results from generalized threshold and sequential models. IZA Discussion Paper No. 1175.

Boes, Stefan, and Rainer Winkelmann. 2006. Ordered response models. Allgemeines Statistisches Archiv, 90, 165-179.

Boes, Stefan, and Rainer Winkelmann. 2010. The effect of income on general life satisfaction and dissatisfaction. Social Indicators Research, 95(1), 111-128.

Chamberlain, Gary. 1980. Multivariate regression models for panel data. Journal of Econometrics, 18, 5-45.

Clark, Andrew E. 2001. What really matters in a job? Hedonic measurement using quit data. Labour Economics, 8, 223-242.

Ferrer-i-Carbonell, Ada, 2005. Income and well-being: an empirical analysis of the comparison income effects. Journal of Public Economics, 89, 997-1019.

Ferrer-i-Carbonell, Ada and Paul Frijters. 2004. How important is methodology for the estimates of the determinants of happiness? Economic Journal, 114, 641-659.

Freeman, Richard B. 1978. Job satisfaction as an economic variable. American Economic Review, 68(2), 135-141. 
Heckman, James J. 1979. Sample selection bias as a specification error. Econometrica, 47(1), 153-161.

Lévy-Garboua, Louis, Claude Montmarquette and Véronique Simonnet. 2007. Job satisfaction and quits. Labour Economics, 14, 251-268.

Mentzakis, Emmanouil. 2011. Allowing heterogeneity in monetary subjective well-being evaluations. Health Economics, 20(3), 331-347.

Mundlak, Yair. 1978. On the pooling of time series and cross section data. Econometrica, 46, 69-85.

Powdthavee, Nattavudh. 2011. Life satisfaction and grandparenthood: evidence from a nationwide survey. Nanyang Technological University: Division of Economics, manuscript.

Powdthavee, Nattavudh and Bernard Van Den Berg. 2011. Putting different price tags on the same health condition: Re-evaluating the well-being valuation method. Journal of Health Economics, forthcoming.

Shields, Michael A., and Melanie Ward. 2001. Improving nurse retention in the National Health Service in England: the impact of job satisfaction on intentions to quit. Journal of Health Economics, 20, 677-701.

Van Praag, Bernard M.S. 1991. Ordinal and cardinal utility: an integration of the two dimensions of the welfare concept. Journal of Econometrics, 50, 69-89. 
Figure 1: The distribution of overall job satisfaction among workers in the private sector and the self-employed, BHPS 1991-2009

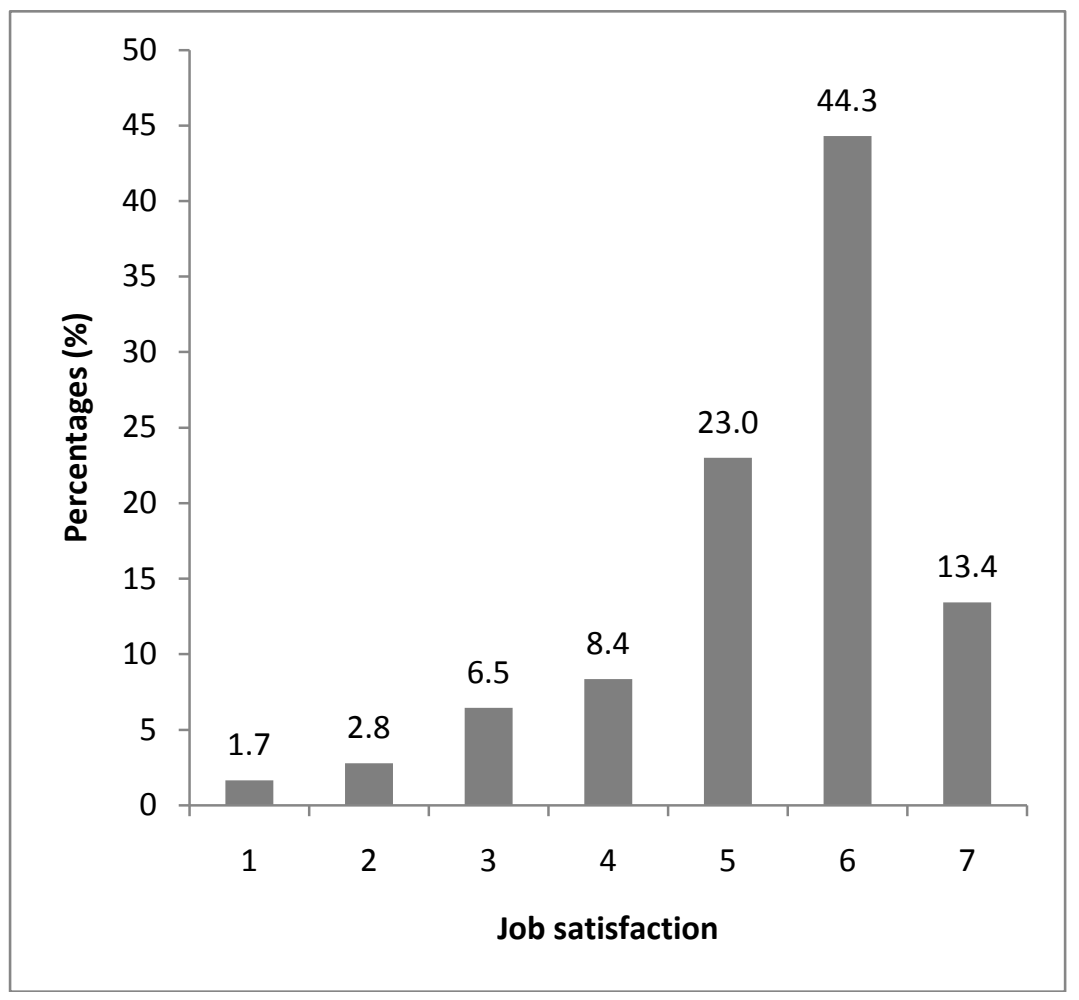

Note: $\mathrm{N}=76,053$. The responses to the overall job satisfaction question range from 1 "very dissatisfied" to 7 "very satisfied". 
Table 1: Standard ordered probit and generalized ordered probit job satisfaction

equations

\begin{tabular}{|c|c|c|c|c|c|c|c|}
\hline \multirow{2}{*}{$\begin{array}{l}\text { Dependent variable: } \\
\text { Overall job satisfaction }\end{array}$} & \multirow{2}{*}{ OPROBIT } & \multicolumn{6}{|c|}{ GOPROBIT } \\
\hline & & $\omega_{1}$ & $\omega_{2}$ & $\omega_{3}$ & $\omega_{4}$ & $\omega_{5}$ & $\omega_{6}$ \\
\hline \multirow[t]{2}{*}{ Log of real pay per month } & $0.107 * *$ & $0.216^{* *}$ & $0.206^{* *}$ & $0.177 * *$ & $0.199 * *$ & $0.148 * *$ & 0.00757 \\
\hline & {$[0.0142]$} & {$[0.0352]$} & {$[0.0251]$} & {$[0.0198]$} & {$[0.0182]$} & {$[0.0170]$} & {$[0.0205]$} \\
\hline \multirow[t]{2}{*}{ Job tenure } & -0.00394 & 0.0117 & -0.0108 & $-0.0179 *$ & $-0.0130 *$ & -0.000970 & 0.000167 \\
\hline & {$[0.00491]$} & {$[0.0136]$} & {$[0.00982]$} & {$[0.00764]$} & {$[0.00655]$} & {$[0.00574]$} & {$[0.00706]$} \\
\hline \multirow[t]{2}{*}{ Job tenure ${ }^{\wedge} 2$} & -0.000498 & -0.000114 & 0.000891 & 0.000787 & 0.000393 & $-0.00076+$ & $-0.0013^{* *}$ \\
\hline & {$[0.000336]$} & {$[0.000938]$} & {$[0.000674]$} & {$[0.000523]$} & {$[0.000451]$} & [0.000394] & {$[0.000488]$} \\
\hline \multirow[t]{2}{*}{ Job size: $10-49$ people } & $-0.148 * *$ & -0.0384 & -0.0387 & $-0.0687 * *$ & $-0.102 * *$ & $-0.157 * *$ & $-0.176 * *$ \\
\hline & {$[0.0163]$} & {$[0.0388]$} & {$[0.0280]$} & {$[0.0227]$} & {$[0.0206]$} & {$[0.0190]$} & {$[0.0216]$} \\
\hline \multirow[t]{2}{*}{ Job size 2: 50-499 } & $-0.288 * *$ & $-0.182 * *$ & $-0.186 * *$ & $-0.203 * *$ & $-0.236^{* *}$ & $-0.298 * *$ & $-0.332 * *$ \\
\hline & {$[0.0174]$} & [0.0397] & {$[0.0289]$} & {$[0.0235]$} & {$[0.0220]$} & {$[0.0206]$} & {$[0.0240]$} \\
\hline \multirow[t]{2}{*}{ Job size $3: 500+$} & $-0.282 * *$ & $-0.202 * *$ & $-0.252 * *$ & $-0.205^{* *}$ & $-0.244 * *$ & $-0.291 * *$ & $-0.312 * *$ \\
\hline & {$[0.0225]$} & {$[0.0521]$} & {$[0.0389]$} & {$[0.0317]$} & {$[0.0291]$} & {$[0.0271]$} & {$[0.0327]$} \\
\hline \multirow[t]{2}{*}{ Pension scheme } & $-0.0542 * *$ & -0.00103 & $-0.0461+$ & $-0.0639 * *$ & $-0.0516^{* *}$ & $-0.0480 * *$ & $-0.0703 * *$ \\
\hline & {$[0.0137]$} & {$[0.0327]$} & {$[0.0240]$} & [0.0191] & {$[0.0176]$} & {$[0.0163]$} & {$[0.0201]$} \\
\hline \multirow[t]{2}{*}{ Union member } & $-0.0735^{* *}$ & -0.0447 & $-0.0693+$ & $-0.131 * *$ & $-0.126^{* *}$ & $-0.0956 * *$ & -0.00207 \\
\hline & {$[0.0215]$} & {$[0.0557]$} & {$[0.0400]$} & {$[0.0321]$} & {$[0.0290]$} & {$[0.0273]$} & {$[0.0348]$} \\
\hline \multirow[t]{2}{*}{ Promotion opportunity } & $0.263 * *$ & $0.359 * *$ & $0.360 * *$ & $0.345^{* *}$ & $0.335^{* *}$ & $0.262 * *$ & $0.180 * *$ \\
\hline & {$[0.0118]$} & {$[0.0293]$} & {$[0.0211]$} & {$[0.0167]$} & {$[0.0152]$} & {$[0.0141]$} & {$[0.0181]$} \\
\hline \multirow[t]{2}{*}{ Permanent job } & $0.203 * *$ & 0.0744 & $0.156^{* *}$ & $0.176^{* *}$ & $0.192 * *$ & $0.208 * *$ & $0.166^{* *}$ \\
\hline & {$[0.0201]$} & {$[0.0495]$} & {$[0.0351]$} & {$[0.0277]$} & {$[0.0252]$} & {$[0.0230]$} & {$[0.0291]$} \\
\hline \multirow[t]{2}{*}{ Commute: $16-30$ minutes } & $-0.0582 * *$ & -0.0218 & $-0.0506^{*}$ & $-0.0565^{* *}$ & $-0.0600 * *$ & $-0.0659 * *$ & $-0.0525 * *$ \\
\hline & {$[0.0130]$} & {$[0.0310]$} & & {$[0.0181]$} & {$[0.0166]$} & {$[0.0156]$} & {$[0.0189]$} \\
\hline \multirow[t]{2}{*}{ Commute:31-60 minutes } & $-0.0837 * *$ & -0.00818 & $-0.0485+$ & $-0.0830 * *$ & $-0.0856^{* *}$ & $-0.0940 * *$ & $-0.0905 * *$ \\
\hline & {$[0.0166]$} & {$[0.0395]$} & & {$[0.0230]$} & {$[0.0219]$} & {$[0.0205]$} & {$[0.0256]$} \\
\hline \multirow[t]{2}{*}{ Commute: $61-90$ minutes } & $-0.205^{* *}$ & $-0.151+$ & $-0.171 * *$ & $-0.234 * *$ & $-0.215^{* *}$ & $-0.228 * *$ & $-0.209 * *$ \\
\hline & {$[0.0350]$} & {$[0.0790]$} & {$[0.0608]$} & {$[0.0518]$} & {$[0.0464]$} & {$[0.0441]$} & {$[0.0575]$} \\
\hline \multirow[t]{2}{*}{ Commute: $91+$ minutes } & -0.0319 & 0.199 & -0.0751 & $-0.149 *$ & $-0.170 * *$ & -0.0418 & 0.0753 \\
\hline & {$[0.0540]$} & [0.167] & {$[0.0892]$} & {$[0.0704]$} & {$[0.0640]$} & {$[0.0602]$} & {$[0.0860]$} \\
\hline \multirow[t]{2}{*}{$\log$ of hours worked pw } & $-0.281 * *$ & $-0.354 * *$ & $-0.400 * *$ & $-0.375 * *$ & $-0.366^{* *}$ & $-0.309 * *$ & $-0.155^{* *}$ \\
\hline & {$[0.0191]$} & {$[0.0508]$} & {$[0.0355]$} & {$[0.0275]$} & [0.0244] & {$[0.0222]$} & {$[0.0262]$} \\
\hline \multirow[t]{2}{*}{ Self-employed } & 0.0509 & -0.125 & 0.00135 & -0.0145 & 0.0249 & 0.0517 & 0.126 \\
\hline & {$[0.0651]$} & [0.179] & {$[0.131]$} & {$[0.101]$} & {$[0.0860]$} & {$[0.0762]$} & [0.0926] \\
\hline \multirow[t]{2}{*}{ Inverse Mill's ratio } & $0.253 * *$ & $0.149^{*}$ & $0.153 * *$ & $0.196^{* *}$ & $0.207 * *$ & $0.230 * *$ & $0.321 * *$ \\
\hline & [0.0293] & [0.0669] & [0.0490] & [0.0400] & {$[0.0362]$} & {$[0.0334]$} & {$[0.0375]$} \\
\hline Log likelihood & -112381.2 & & & -110408 & & & \\
\hline
\end{tabular}

Note: $+<10 \% ; *<5 \% ; * *<1 \%$. N=76,053. Standard errors are in parentheses. Reference groups are: job size: 1-9 people and commute: 0-15 minutes. Control variables include: age, age-squared, gender, health status, marital status, education, race dummies (3), occupational sector dummies (35), regional dummies (19), and wave dummies (18). 
Table 2: Generalized ordered probit job satisfaction equation with random effects

\begin{tabular}{|c|c|c|c|c|c|c|}
\hline \multirow{2}{*}{$\begin{array}{l}\text { Dependent variable: Overall } \\
\text { job satisfaction }\end{array}$} & \multicolumn{6}{|c|}{ RE-GOPROBIT } \\
\hline & $\omega_{1}$ & $\omega_{2}$ & $\omega_{3}$ & $\omega_{4}$ & $\omega_{5}$ & $\omega_{6}$ \\
\hline \multirow[t]{2}{*}{ Log of real pay per month } & $0.264 * *$ & $0.261 * *$ & $0.232 * *$ & $0.261 * *$ & $0.203^{* *}$ & $0.0313+$ \\
\hline & {$[0.0364]$} & {$[0.0261]$} & [0.0203] & {$[0.0178]$} & {$[0.0158]$} & {$[0.0190]$} \\
\hline \multirow[t]{2}{*}{ Job tenure } & 0.0208 & -0.00500 & -0.0131 & -0.00785 & 0.00855 & $0.0187 *$ \\
\hline & {$[0.0154]$} & {$[0.0112]$} & {$[0.00865]$} & {$[0.00746]$} & {$[0.00644]$} & {$[0.00803]$} \\
\hline \multirow[t]{2}{*}{ Job tenure ${ }^{\wedge} 2$} & -0.00058 & 0.00045 & 0.00022 & -0.00030 & $-0.0020 * *$ & $-0.0035^{* *}$ \\
\hline & {$[0.00106]$} & {$[0.000763]$} & [0.000589] & {$[0.000508]$} & {$[0.000440]$} & {$[0.000552]$} \\
\hline \multirow[t]{2}{*}{ Job size: $10-49$ people } & -0.0400 & -0.0458 & $-0.0831 * *$ & $-0.125 * *$ & $-0.188 * *$ & $-0.197 * *$ \\
\hline & {$[0.0402]$} & {$[0.0293]$} & {$[0.0226]$} & {$[0.0198]$} & {$[0.0173]$} & {$[0.0206]$} \\
\hline \multirow[t]{2}{*}{ Job size 2: 50-499 } & $-0.156 * *$ & $-0.176^{* *}$ & $-0.200 * *$ & $-0.245 * *$ & $-0.321 * *$ & $-0.345^{* *}$ \\
\hline & {$[0.0418]$} & {$[0.0302]$} & {$[0.0235]$} & {$[0.0209]$} & {$[0.0186]$} & {$[0.0232]$} \\
\hline \multirow[t]{2}{*}{ Job size $3: 500+$} & $-0.167 * *$ & $-0.237 * *$ & $-0.187 * *$ & $-0.238 * *$ & $-0.297 * *$ & $-0.309 * *$ \\
\hline & {$[0.0539]$} & {$[0.0386]$} & {$[0.0303]$} & [0.0269] & {$[0.0241]$} & {$[0.0312]$} \\
\hline \multirow[t]{2}{*}{ Pension scheme } & 0.0476 & -0.00425 & -0.0316 & -0.0217 & -0.0241 & $-0.0667 * *$ \\
\hline & {$[0.0344]$} & {$[0.0251]$} & {$[0.0194]$} & {$[0.0171]$} & {$[0.0151]$} & [0.0193] \\
\hline \multirow{2}{*}{ Union member } & 0.0241 & -0.0167 & $-0.110 * *$ & $-0.119 * *$ & $-0.109 * *$ & -0.0239 \\
\hline & {$[0.0566]$} & {$[0.0400]$} & [0.0307] & {$[0.0270]$} & {$[0.0242]$} & {$[0.0337]$} \\
\hline \multirow{2}{*}{ Promotion opportunity } & $0.388 * *$ & $0.398 * *$ & $0.393 * *$ & $0.389 * *$ & $0.316^{* *}$ & $0.235^{* *}$ \\
\hline & {$[0.0322]$} & {$[0.0224]$} & {$[0.0170]$} & [0.0149] & {$[0.0132]$} & {$[0.0173]$} \\
\hline \multirow[t]{2}{*}{ Permanent job } & 0.0648 & $0.162 * *$ & $0.189 * *$ & $0.201 * *$ & $0.207 * *$ & $0.138 * *$ \\
\hline & {$[0.0540]$} & {$[0.0392]$} & {$[0.0311]$} & {$[0.0274]$} & {$[0.0250]$} & {$[0.0318]$} \\
\hline \multirow[t]{2}{*}{ Commute: $16-30$ minutes } & 0.0183 & -0.0146 & -0.0244 & $-0.0312 *$ & $-0.0407 * *$ & -0.0197 \\
\hline & {$[0.0317]$} & {$[0.0229]$} & {$[0.0180]$} & {$[0.0159]$} & {$[0.0142]$} & {$[0.0181]$} \\
\hline \multirow[t]{2}{*}{ Commute:31-60 minutes } & 0.0319 & -0.0121 & $-0.0582 *$ & $-0.0670 * *$ & $-0.0841 * *$ & $-0.0618^{*}$ \\
\hline & {$[0.0420]$} & {$[0.0300]$} & {$[0.0232]$} & {$[0.0206]$} & {$[0.0185]$} & {$[0.0245]$} \\
\hline \multirow[t]{2}{*}{ Commute: $61-90$ minutes } & -0.0935 & $-0.113+$ & $-0.202 * *$ & $-0.183 * *$ & $-0.207 * *$ & $-0.183^{* *}$ \\
\hline & {$[0.0885]$} & {$[0.0624]$} & {$[0.0467]$} & {$[0.0422]$} & {$[0.0383]$} & {$[0.0566]$} \\
\hline \multirow[t]{2}{*}{ Commute: $91+$ minutes } & 0.242 & -0.120 & $-0.196 * *$ & $-0.222 * *$ & -0.0560 & 0.104 \\
\hline & {$[0.205]$} & [0.104] & {$[0.0760]$} & {$[0.0672]$} & {$[0.0606]$} & {$[0.0782]$} \\
\hline \multirow[t]{2}{*}{$\log$ of hours worked pw } & $-0.426 * *$ & $-0.496 * *$ & $-0.475 * *$ & $-0.470 * *$ & $-0.406 * *$ & $-0.217 * *$ \\
\hline & {$[0.0492]$} & {$[0.0358]$} & {$[0.0277]$} & {$[0.0241]$} & {$[0.0211]$} & {$[0.0244]$} \\
\hline \multirow[t]{2}{*}{ Self-employed } & -0.138 & -0.00361 & -0.0266 & 0.0389 & 0.0750 & 0.152 \\
\hline & [0.198] & {$[0.151]$} & {$[0.115]$} & {$[0.101]$} & {$[0.0861]$} & [0.105] \\
\hline \multirow[t]{2}{*}{ Inverse Mill's ratio } & $0.129+$ & $0.125^{*}$ & $0.175^{* *}$ & $0.184 * *$ & $0.212 * *$ & $0.321 * *$ \\
\hline & {$[0.0702]$} & {$[0.0520]$} & {$[0.0413]$} & {$[0.0362]$} & {$[0.0322]$} & {$[0.0378]$} \\
\hline
\end{tabular}

Note: $\mathrm{N}=76,053$. Log likelihood $=-104329.27$. Also see Table 1 . 
Table 3: Generalized ordered probit job satisfaction equation with random effects and

Mundlak transformations

\begin{tabular}{|c|c|c|c|c|c|c|}
\hline \multirow{2}{*}{$\begin{array}{l}\text { Dependent variable: Overall } \\
\text { job satisfaction }\end{array}$} & \multicolumn{6}{|c|}{ RE-GOPROBIT-ML } \\
\hline & $\theta_{1}$ & $\theta_{2}$ & $\theta_{3}$ & $\theta_{4}$ & $\theta_{5}$ & $\theta_{6}$ \\
\hline \multicolumn{7}{|l|}{ Current job characteristics } \\
\hline \multirow[t]{2}{*}{ Log of real pay per month } & $0.237 * *$ & $0.256^{* *}$ & $0.251 * *$ & $0.285^{* *}$ & $0.238 * *$ & $0.113 * *$ \\
\hline & {$[0.0485]$} & {$[0.0332]$} & {$[0.0258]$} & {$[0.0222]$} & {$[0.0193]$} & {$[0.0240]$} \\
\hline \multirow[t]{2}{*}{ Job tenure } & 0.0276 & 0.00213 & -0.00642 & $8.35 \mathrm{e}-05$ & $0.0118+$ & $0.0148+$ \\
\hline & {$[0.0171]$} & {$[0.0122]$} & {$[0.00930]$} & {$[0.00795]$} & {$[0.00682]$} & [0.0086] \\
\hline \multirow[t]{2}{*}{ Job tenure ${ }^{\wedge} 2$} & -0.0018 & -0.00077 & -0.0009 & $-0.0013^{*}$ & $-0.003 * *$ & $-0.003 * *$ \\
\hline & {$[0.00117]$} & {$[0.0008]$} & {$[0.00063]$} & {$[0.00054]$} & {$[0.00046]$} & [0.0005] \\
\hline \multirow[t]{2}{*}{ Job size: $10-49$ people } & -0.0309 & $-0.0592+$ & $-0.090 * *$ & $-0.127 * *$ & $-0.159 * *$ & $-0.160 * *$ \\
\hline & {$[0.0503]$} & {$[0.0359]$} & {$[0.0273]$} & {$[0.0235]$} & [0.0203] & [0.0253] \\
\hline \multirow[t]{2}{*}{ Job size 2: 50-499 } & $-0.135^{*}$ & $-0.134 * *$ & $-0.157 * *$ & $-0.209 * *$ & $-0.255^{* *}$ & $-0.275^{* *}$ \\
\hline & {$[0.0530]$} & {$[0.0377]$} & {$[0.0291]$} & {$[0.0253]$} & {$[0.0223]$} & [0.0294] \\
\hline \multirow[t]{2}{*}{ Job size 3: $500+$} & -0.0714 & $-0.143 * *$ & $-0.148 * *$ & $-0.184 * *$ & $-0.211 * *$ & $-0.232 * *$ \\
\hline & {$[0.0681]$} & {$[0.0484]$} & {$[0.0373]$} & {$[0.0326]$} & {$[0.0288]$} & [0.0395] \\
\hline \multirow[t]{2}{*}{ Pension scheme } & 0.0320 & -0.0363 & -0.0158 & 0.00576 & -0.00727 & -0.0306 \\
\hline & {$[0.0416]$} & {$[0.0303]$} & {$[0.0230]$} & [0.0199] & {$[0.0174]$} & [0.0229] \\
\hline \multirow[t]{2}{*}{ Union member } & -0.0395 & -0.0460 & $-0.123 * *$ & $-0.125 * *$ & $-0.096^{* *}$ & -0.0646 \\
\hline & {$[0.0701]$} & {$[0.0498]$} & {$[0.0375]$} & {$[0.0326]$} & {$[0.0287]$} & [0.0412] \\
\hline \multirow[t]{2}{*}{ Promotion opportunity } & $0.446^{* *}$ & $0.431 * *$ & $0.430 * *$ & $0.391 * *$ & $0.303 * *$ & $0.230 * *$ \\
\hline & {$[0.0381]$} & {$[0.0263]$} & {$[0.0196]$} & {$[0.0170]$} & {$[0.0149]$} & [0.0203] \\
\hline \multirow[t]{2}{*}{ Permanent job } & 0.0753 & $0.142 * *$ & $0.134 * *$ & $0.156^{* *}$ & $0.184^{* *}$ & 0.0421 \\
\hline & {$[0.0658]$} & {$[0.0468]$} & {$[0.0366]$} & {$[0.0322]$} & {$[0.0291]$} & [0.0381] \\
\hline \multirow[t]{2}{*}{ Commute: $16-30$ minutes } & 0.0134 & -0.0398 & -0.0200 & -0.0183 & -0.00665 & 0.0260 \\
\hline & {$[0.0394]$} & {$[0.0283]$} & {$[0.0218]$} & {$[0.0190]$} & {$[0.0167]$} & [0.0223] \\
\hline \multirow[t]{2}{*}{ Commute:31-60 minutes } & 0.0252 & 0.0103 & -0.0392 & $-0.0491+$ & -0.0305 & 0.0155 \\
\hline & {$[0.0538]$} & {$[0.0382]$} & {$[0.0289]$} & {$[0.0252]$} & {$[0.0223]$} & [0.0305] \\
\hline \multirow[t]{2}{*}{ Commute: $61-90$ minutes } & -0.135 & -0.0476 & $-0.194 * *$ & $-0.175^{* *}$ & $-0.157 * *$ & -0.0998 \\
\hline & [0.111] & {$[0.0760]$} & {$[0.0557]$} & {$[0.0492]$} & {$[0.0438]$} & [0.0664] \\
\hline \multirow[t]{2}{*}{ Commute: $91+$ minutes } & $0.508^{*}$ & -0.00434 & -0.128 & $-0.194 *$ & -0.0463 & -0.00314 \\
\hline & {$[0.247]$} & {$[0.120]$} & {$[0.0891]$} & {$[0.0776]$} & {$[0.0685]$} & [0.0925] \\
\hline \multirow[t]{2}{*}{$\log$ of hours worked pw } & $-0.391 * *$ & $-0.502 * *$ & $-0.500 * *$ & $-0.495 * *$ & $-0.422 * *$ & $-0.303 * *$ \\
\hline & {$[0.0648]$} & {$[0.0459]$} & {$[0.0351]$} & {$[0.0301]$} & {$[0.0259]$} & [0.0314] \\
\hline \multirow[t]{2}{*}{ Self-employed } & -0.0985 & 0.0381 & 0.0328 & 0.0202 & 0.0678 & 0.160 \\
\hline & {$[0.202]$} & [0.154] & [0.118] & [0.103] & {$[0.0873]$} & [0.106] \\
\hline \multicolumn{7}{|l|}{ Within person averages } \\
\hline \multirow[t]{2}{*}{ Log of real pay per month } & 0.0167 & -0.0273 & $-0.0770 *$ & $-0.085^{* *}$ & $-0.092 * *$ & $-0.171 * *$ \\
\hline & {$[0.0638]$} & {$[0.0450]$} & [0.0359] & {$[0.0321]$} & {$[0.0288]$} & [0.0343] \\
\hline \multirow[t]{2}{*}{ Job tenure } & $-0.0740+$ & $-0.083 * *$ & $-0.082 * *$ & $-0.087 * *$ & $-0.059 * *$ & -0.0164 \\
\hline & {$[0.0428]$} & {$[0.0319]$} & {$[0.0262]$} & [0.0239] & {$[0.0220]$} & [0.0259] \\
\hline \multirow[t]{2}{*}{ Job tenure ${ }^{\wedge} 2$} & $0.0099 * *$ & $0.010 * *$ & $0.0098 * *$ & $0.0096^{* *}$ & $0.0068 * *$ & 0.00201 \\
\hline & {$[0.00296]$} & {$[0.0022]$} & {$[0.00182]$} & {$[0.00166]$} & {$[0.00153]$} & [0.0018] \\
\hline
\end{tabular}




\begin{tabular}{lcccccc} 
Job size: 10-49 people & $0.303 * *$ & $0.278^{* *}$ & $0.130+$ & $0.164 *$ & $0.259^{* *}$ & $0.226^{* *}$ \\
Job size 2: 50-499 & {$[0.114]$} & {$[0.0879]$} & {$[0.0716]$} & {$[0.0651]$} & {$[0.0598]$} & {$[0.0727]$} \\
& $0.269 * *$ & $0.310^{* *}$ & $0.145^{*}$ & $0.164 * *$ & $0.166^{* *}$ & $0.128^{*}$ \\
Job size 3: 500+ & {$[0.0984]$} & {$[0.0772]$} & {$[0.0628]$} & {$[0.0569]$} & {$[0.0524]$} & {$[0.0652]$} \\
Pension scheme & $0.0941^{*}$ & 0.0541 & -0.0128 & 0.0152 & 0.0207 & 0.00852 \\
& {$[0.0456]$} & {$[0.0355]$} & {$[0.0292]$} & {$[0.0267]$} & {$[0.0248]$} & {$[0.0312]$} \\
Union member & -0.0486 & -0.00883 & $-0.128^{*}$ & $-0.149 * *$ & $-0.0950^{*}$ & $-0.131^{* *}$ \\
& {$[0.0857]$} & {$[0.0641]$} & {$[0.0517]$} & {$[0.0469]$} & {$[0.0428]$} & {$[0.0503]$} \\
Promotion opportunity & -0.115 & -0.0471 & -0.0518 & -0.0471 & -0.0199 & $-0.158^{*}$ \\
& {$[0.122]$} & {$[0.0893]$} & {$[0.0716]$} & {$[0.0650]$} & {$[0.0598]$} & {$[0.0744]$} \\
Permanent job & $0.160 *$ & 0.0828 & $0.103 *$ & -0.0148 & $-0.0678+$ & -0.0237 \\
Commute: $16-30$ minutes & {$[0.0763]$} & {$[0.0566]$} & {$[0.0453]$} & {$[0.0412]$} & {$[0.0378]$} & {$[0.0454]$} \\
Commute:31-60 minutes & -0.0651 & 0.0434 & $0.142 *$ & $0.124 *$ & 0.0750 & $0.303^{* *}$ \\
& {$[0.113]$} & {$[0.0819]$} & {$[0.0677]$} & {$[0.0614]$} & {$[0.0563]$} & {$[0.0689]$} \\
Commute: 61-90 minutes & -0.101 & 0.177 & -0.00727 & 0.0320 & 0.156 & $0.300^{*}$ \\
Inverse Mill's ratio & {$[0.241]$} & {$[0.176]$} & {$[0.144]$} & {$[0.134]$} & {$[0.123]$} & {$[0.153]$} \\
Commute: 91+ minutes & -0.112 & 0.242 & -0.0450 & -0.0347 & 0.0353 & 0.155 \\
& {$[0.243]$} & {$[0.177]$} & {$[0.145]$} & {$[0.134]$} & {$[0.123]$} & {$[0.154]$} \\
log of hours worked pw & -0.0611 & 0.0397 & -0.0455 & -0.0264 & -0.0114 & 0.0265 \\
Self-employed & {$[0.128]$} & {$[0.0926]$} & {$[0.0758]$} & {$[0.0704]$} & {$[0.0647]$} & {$[0.0805]$} \\
& $-0.789+$ & -0.0369 & -0.122 & -0.0182 & 0.217 & $0.737 * *$ \\
& {$[0.456]$} & {$[0.312]$} & {$[0.260]$} & {$[0.240]$} & {$[0.222]$} & {$[0.262]$} \\
& -0.00617 & 0.0638 & $0.107 *$ & $0.0946 *$ & 0.0670 & $0.174 * *$ \\
& {$[0.0930]$} & {$[0.0672]$} & {$[0.0528]$} & {$[0.0470]$} & {$[0.0421]$} & {$[0.0487]$} \\
& -0.0409 & -0.0401 & -0.0699 & 0.126 & 0.0799 & 0.00769 \\
& {$[0.156]$} & {$[0.118]$} & {$[0.0998]$} & {$[0.0913]$} & {$[0.0837]$} & {$[0.0964]$} \\
& $0.163 *$ & $0.169 * *$ & $0.201 * *$ & $0.200 * *$ & $0.219 * *$ & $0.304^{* *}$ \\
& {$[0.0715]$} & {$[0.0520]$} & {$[0.0414]$} & {$[0.0363]$} & {$[0.0323]$} & {$[0.0379]$} \\
\hline
\end{tabular}

Note: $\mathrm{N}=76,053$. Log likelihood $=-103992.11$. See Table 1 . 
Figures 2A-2F: Marginal probability effects of job characteristics on job satisfaction

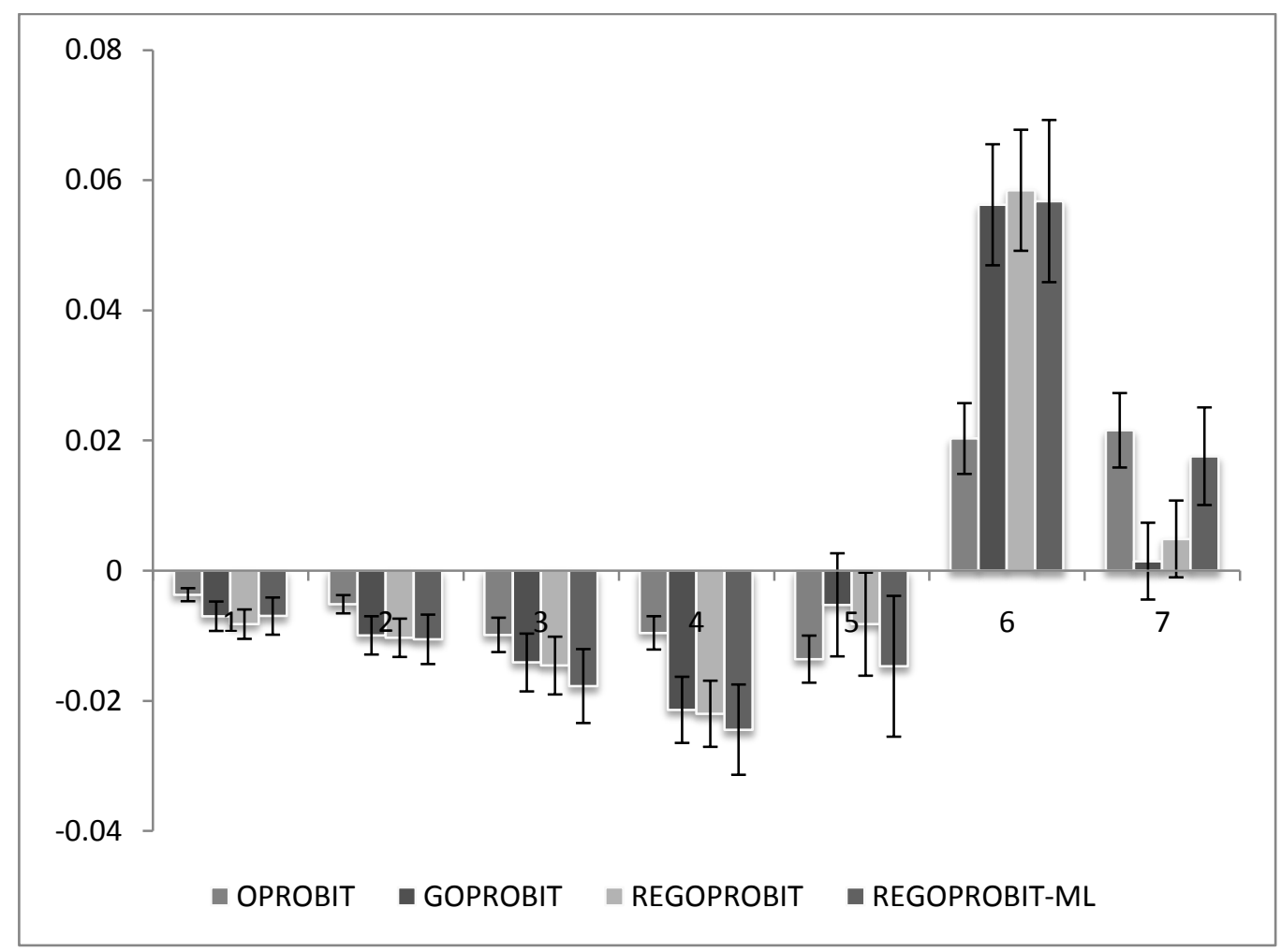

Figure 2A: log of pay per month

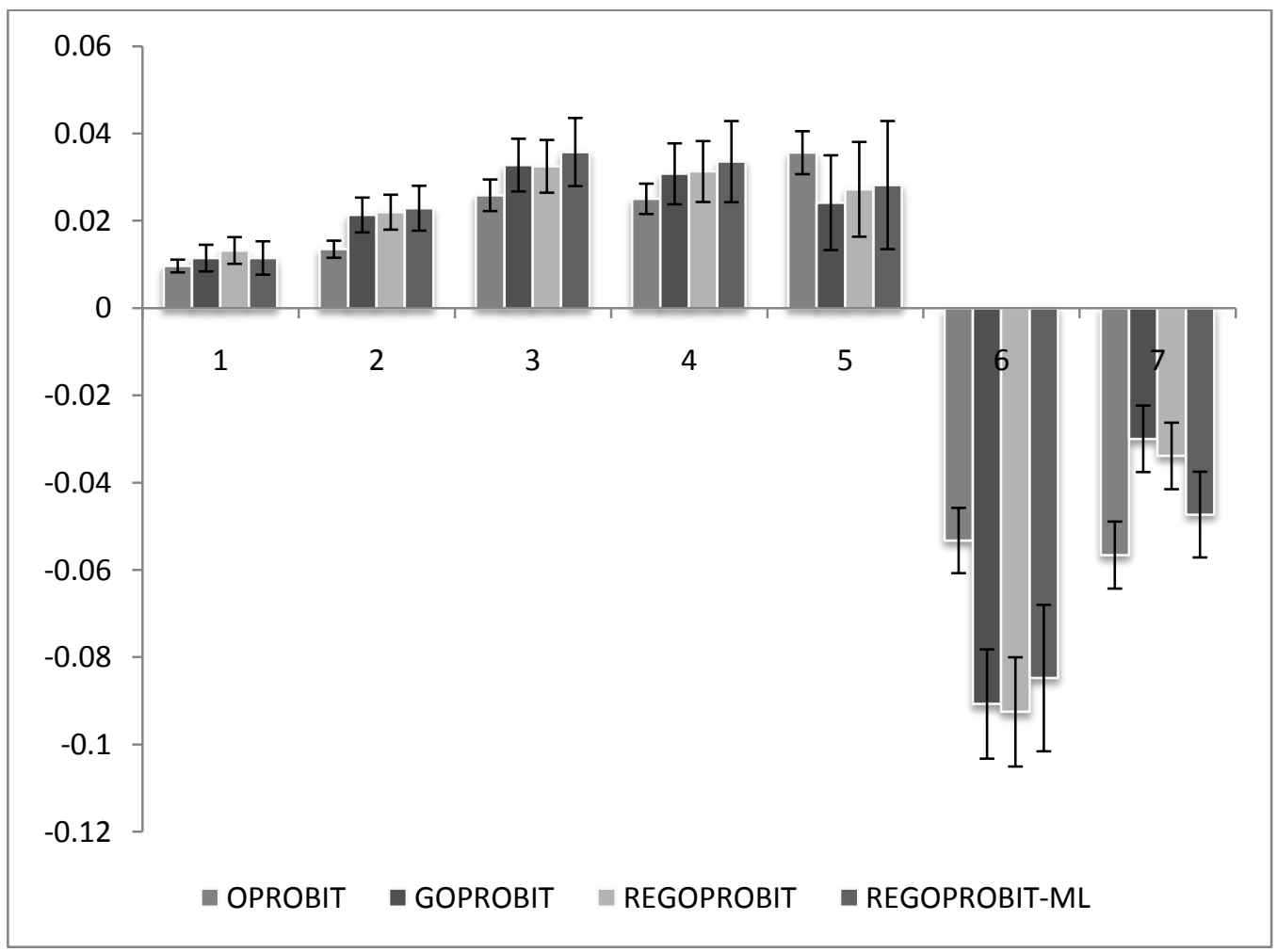

Figure 2B: $\log$ of hours worked per week 


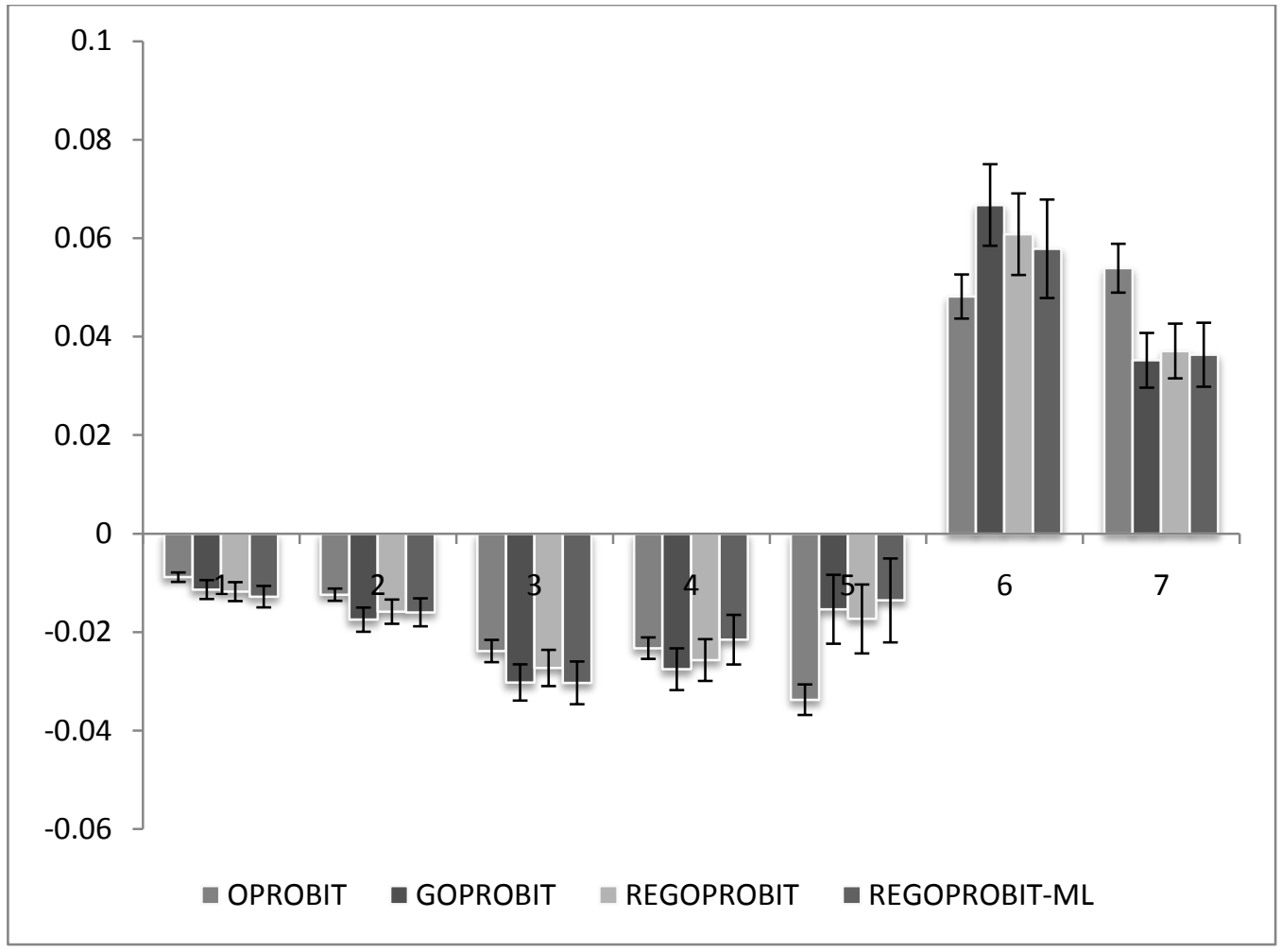

Figure 2C: promotional opportunity*

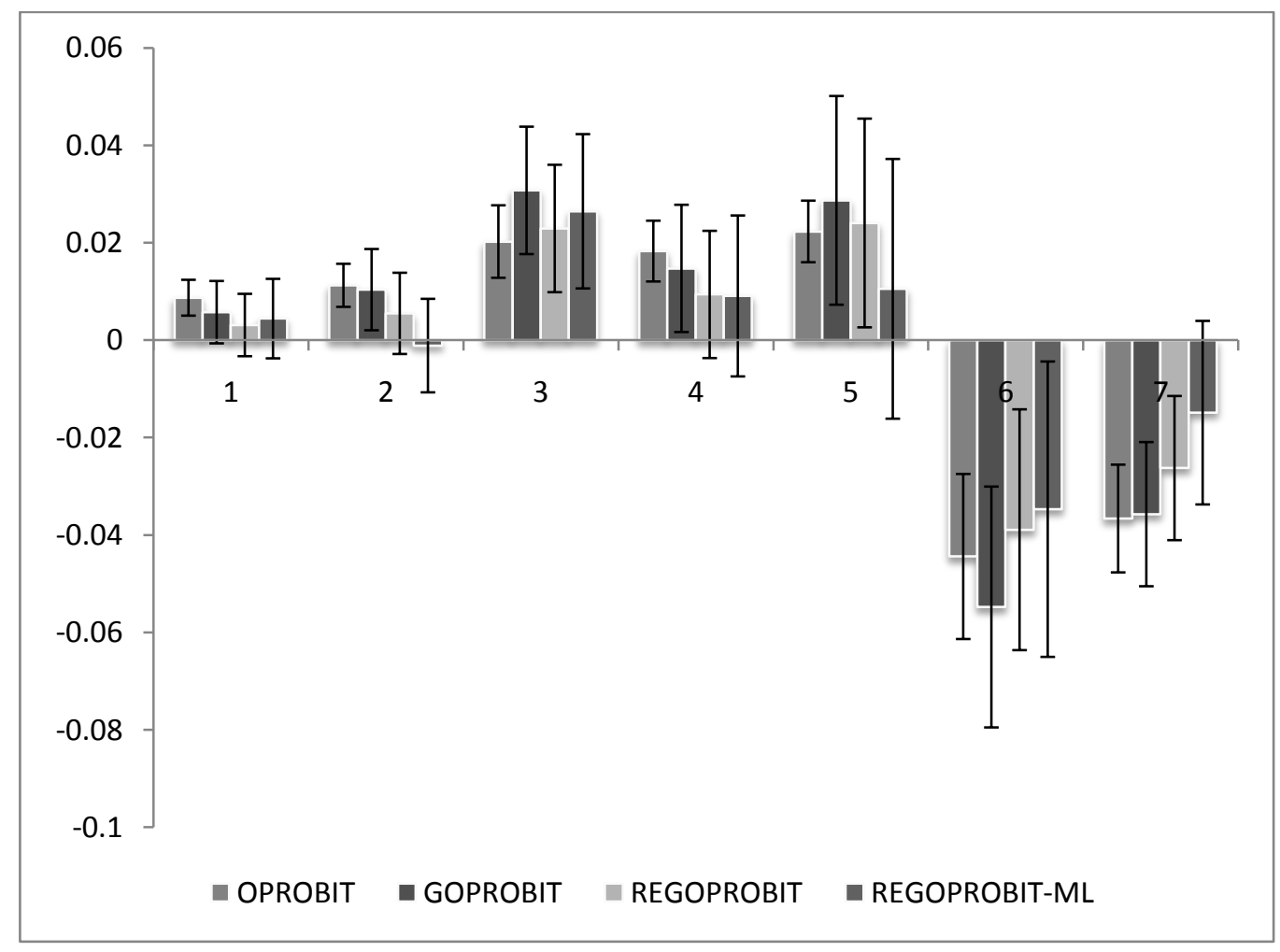

Figure 2D: commuting time: $61-90$ minutes* 


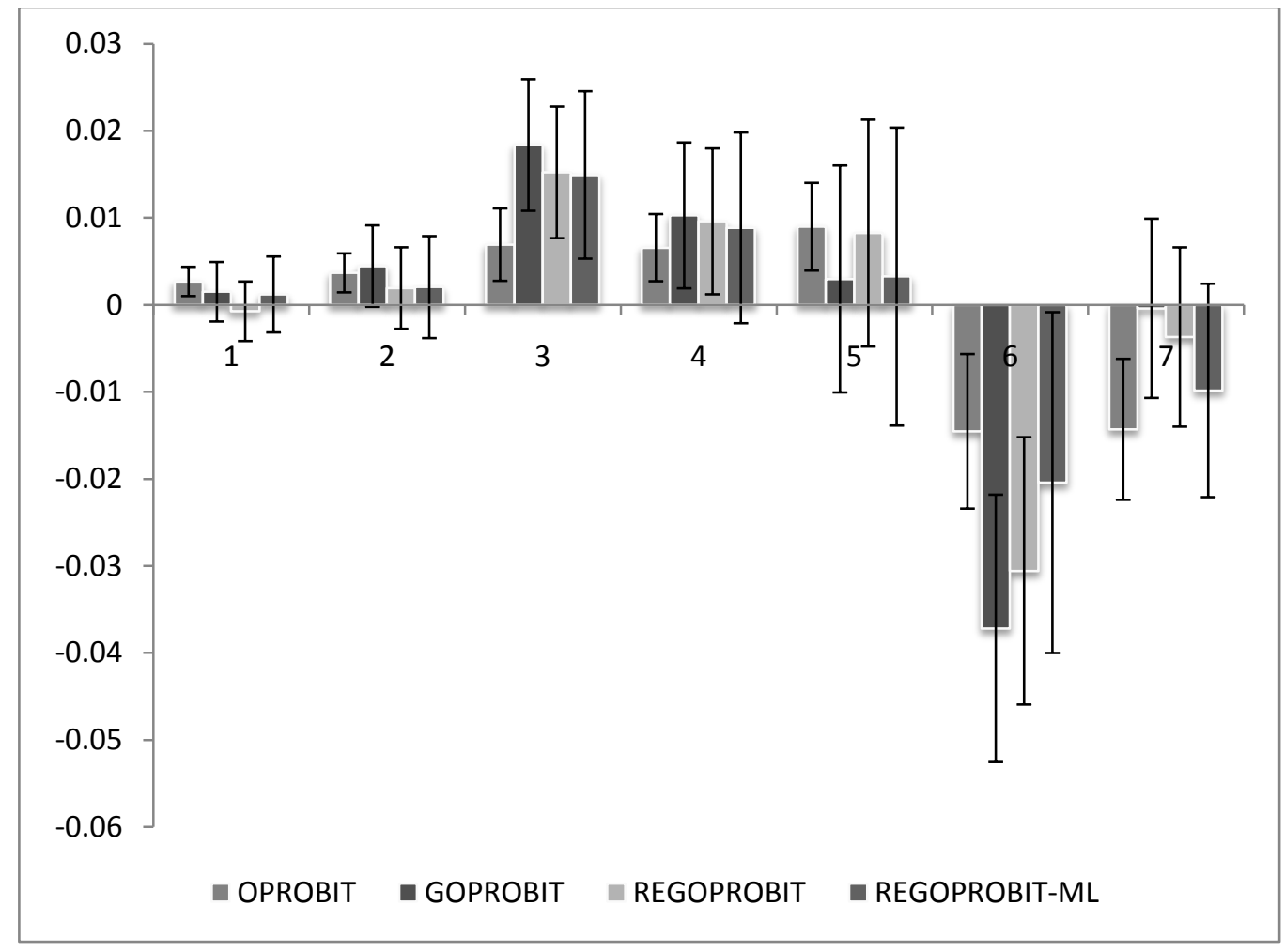

Figure 2E: union membership*

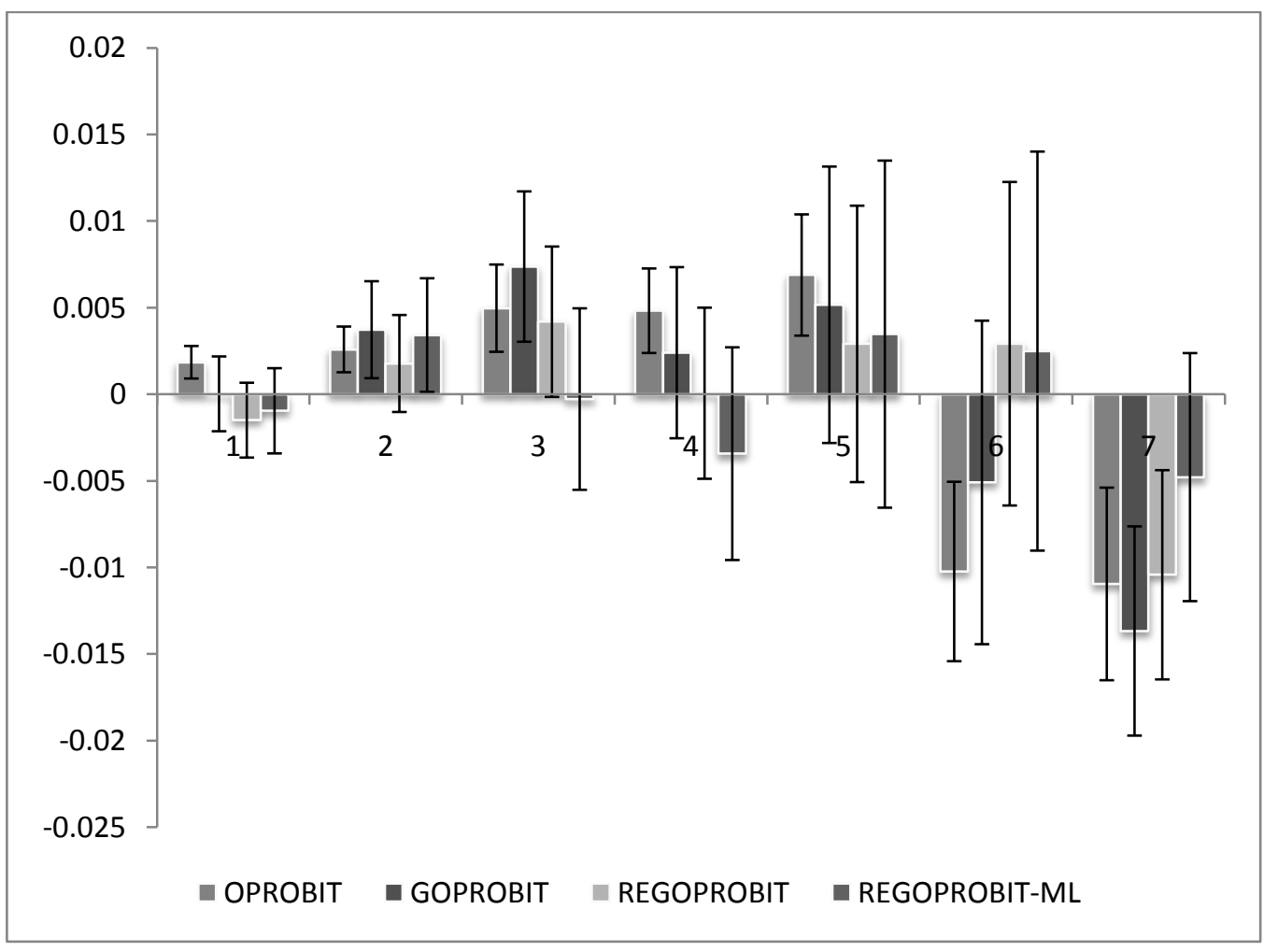

Figure 2F: employer runs a pension scheme*

Note: * denotes the marginal probability effect of a dummy variable. 4-standard-error bars (two above, two below), i.e., $95 \%$ confidence interval. 
Table 4: Normalized Marginal Probability Effects (or MPEs as a \% Change)

\begin{tabular}{|c|c|c|c|c|c|c|c|}
\hline \multirow[b]{2}{*}{ Normalized MPEs } & \multicolumn{7}{|c|}{ Job satisfaction } \\
\hline & 1 & 2 & 3 & 4 & 5 & 6 & 7 \\
\hline \multicolumn{8}{|l|}{ Log of pay per month } \\
\hline OPROBIT & $-21.7 \%$ & $-18.4 \%$ & $-15.2 \%$ & $-11.4 \%$ & $-5.9 \%$ & $4.6 \%$ & $16.1 \%$ \\
\hline GOPROBIT & $-41.2 \%$ & $-35.5 \%$ & $-21.7 \%$ & $-25.5 \%$ & $-2.3 \%$ & $12.7 \%$ & $1.1 \%$ \\
\hline REGOPROBIT & $-48.4 \%$ & $-36.8 \%$ & $-22.4 \%$ & $-26.2 \%$ & $-3.6 \%$ & $13.2 \%$ & $3.6 \%$ \\
\hline REGOPROBIT-ML & $-41.1 \%$ & $-37.7 \%$ & $-27.3 \%$ & $-29.1 \%$ & $-6.4 \%$ & $12.8 \%$ & $13.1 \%$ \\
\hline \multicolumn{8}{|c|}{ Log of hours worked per week } \\
\hline OPROBIT & $56.9 \%$ & $48.3 \%$ & $39.8 \%$ & $29.8 \%$ & $15.5 \%$ & $-12.0 \%$ & $-42.2 \%$ \\
\hline GOPROBIT & $67.6 \%$ & $76.3 \%$ & $50.4 \%$ & $36.7 \%$ & $10.5 \%$ & $-20.5 \%$ & $-22.3 \%$ \\
\hline REGOPROBIT & $67.6 \%$ & $76.3 \%$ & $50.4 \%$ & $36.7 \%$ & $10.5 \%$ & $-20.5 \%$ & $-22.3 \%$ \\
\hline REGOPROBIT-ML & $67.7 \%$ & $81.8 \%$ & $55.1 \%$ & $40.0 \%$ & $12.3 \%$ & $-19.1 \%$ & $-35.3 \%$ \\
\hline \multicolumn{8}{|c|}{ Promotional opportunity } \\
\hline OPROBIT & $-52.0 \%$ & $-44.3 \%$ & $-36.7 \%$ & $-27.7 \%$ & $-14.7 \%$ & $10.9 \%$ & $40.2 \%$ \\
\hline GOPROBIT & $-66.8 \%$ & $-62.4 \%$ & $-46.5 \%$ & $-32.8 \%$ & $-6.7 \%$ & $15.1 \%$ & $26.3 \%$ \\
\hline REGOPROBIT & $-66.8 \%$ & $-62.4 \%$ & $-46.5 \%$ & $-32.8 \%$ & $-6.7 \%$ & $15.1 \%$ & $26.3 \%$ \\
\hline REGOPROBIT-ML & $-75.3 \%$ & $-57.1 \%$ & $-46.6 \%$ & $-25.6 \%$ & $-5.9 \%$ & $13.1 \%$ & $27.1 \%$ \\
\hline \multicolumn{8}{|c|}{ Commuting time: $61-90$ minutes } \\
\hline OPROBIT & $51.4 \%$ & $40.3 \%$ & $31.2 \%$ & $21.8 \%$ & $9.7 \%$ & $-10.0 \%$ & $-27.3 \%$ \\
\hline GOPROBIT & $34.0 \%$ & $37.1 \%$ & $47.3 \%$ & $17.6 \%$ & $12.5 \%$ & $-12.4 \%$ & $-26.6 \%$ \\
\hline REGOPROBIT & $18.5 \%$ & $19.7 \%$ & $35.3 \%$ & $11.2 \%$ & $10.5 \%$ & $-8.8 \%$ & $-19.6 \%$ \\
\hline REGOPROBIT-ML & $26.2 \%$ & $-3.9 \%$ & $40.7 \%$ & $10.8 \%$ & $4.6 \%$ & $-7.8 \%$ & $-11.1 \%$ \\
\hline \multicolumn{8}{|l|}{ Union membership } \\
\hline OPROBIT & $15.8 \%$ & $13.1 \%$ & $10.6 \%$ & $7.8 \%$ & $3.9 \%$ & $-3.3 \%$ & $-10.7 \%$ \\
\hline GOPROBIT & $8.9 \%$ & $15.9 \%$ & $28.3 \%$ & $12.2 \%$ & $1.3 \%$ & $-8.4 \%$ & $-0.3 \%$ \\
\hline REGOPROBIT & $-4.3 \%$ & $6.9 \%$ & $23.4 \%$ & $11.4 \%$ & $3.6 \%$ & $-6.9 \%$ & $-2.8 \%$ \\
\hline REGOPROBIT-ML & $7.0 \%$ & $7.3 \%$ & $23.0 \%$ & $10.5 \%$ & $1.4 \%$ & $-4.6 \%$ & $-7.3 \%$ \\
\hline \multicolumn{8}{|c|}{ Employer runs a pension scheme } \\
\hline OPROBIT & $10.9 \%$ & $9.3 \%$ & $7.7 \%$ & $5.8 \%$ & $3.0 \%$ & $-2.3 \%$ & $-8.2 \%$ \\
\hline GOPROBIT & $0.2 \%$ & $13.3 \%$ & $11.4 \%$ & $2.9 \%$ & $2.3 \%$ & $-1.1 \%$ & $-10.2 \%$ \\
\hline REGOPROBIT & $-8.7 \%$ & $6.4 \%$ & $6.5 \%$ & $0.1 \%$ & $1.3 \%$ & $0.7 \%$ & $-7.8 \%$ \\
\hline REGOPROBIT-ML & $-5.6 \%$ & $12.2 \%$ & $-0.4 \%$ & $-4.1 \%$ & $1.5 \%$ & $0.6 \%$ & $-3.6 \%$ \\
\hline
\end{tabular}

Note: Normalized MPEs (or the percentage change in the job satisfaction distribution) are calculated by dividing the estimated MPE (Figures $2 \mathrm{~A}-2 \mathrm{~F}$ ) by the proportion of people reporting to be in the corresponding job satisfaction category (see Figure 1). 
Figures 3A-3C: Trade-off ratios between variables

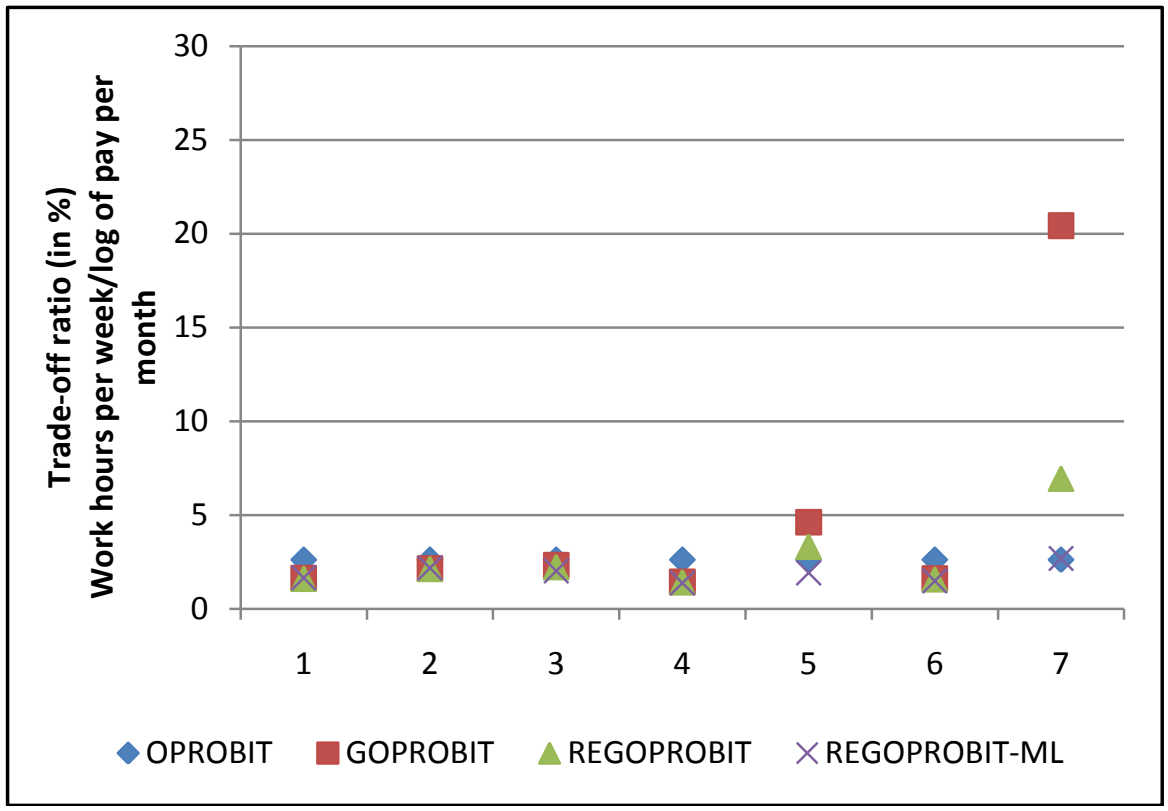

Figure 3A: How much additional pay per month (in \%) is required to compensate a 1\% increase in the number of hours work per week?

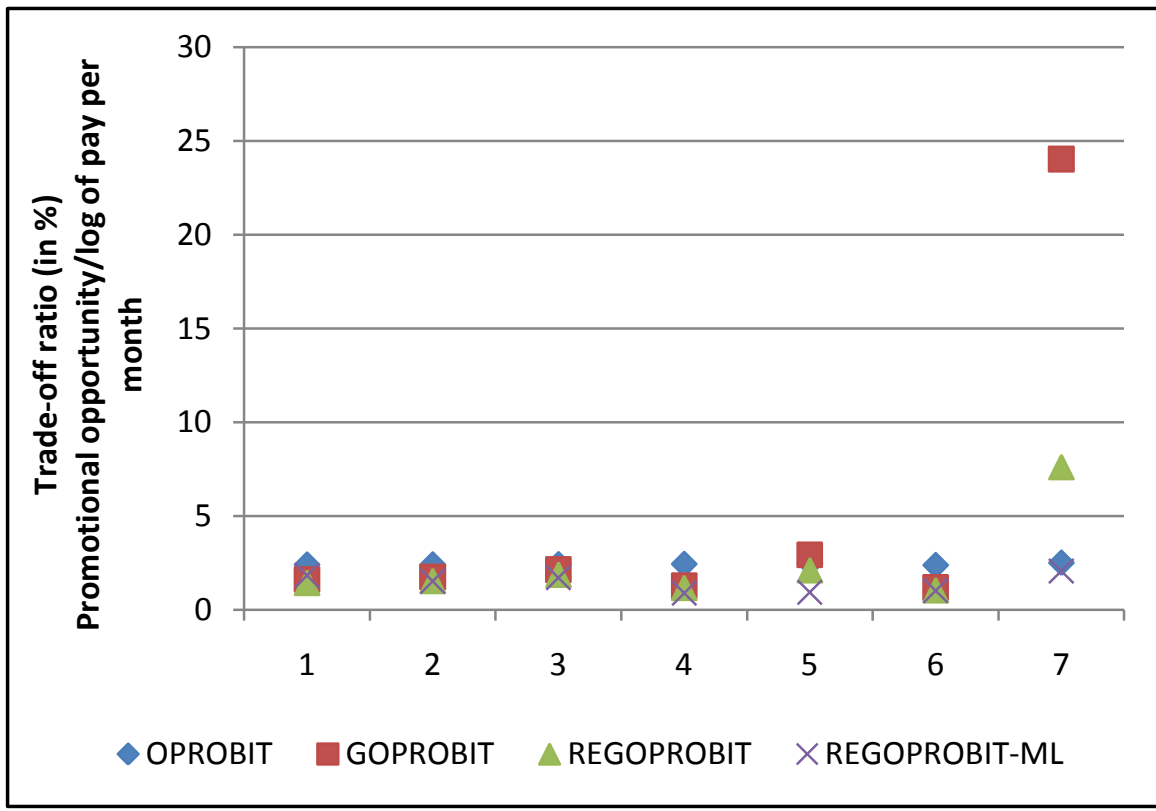

Figure 3B: How much additional pay per month (in \%) is equivalent to having promotional opportunity at the workplace? 


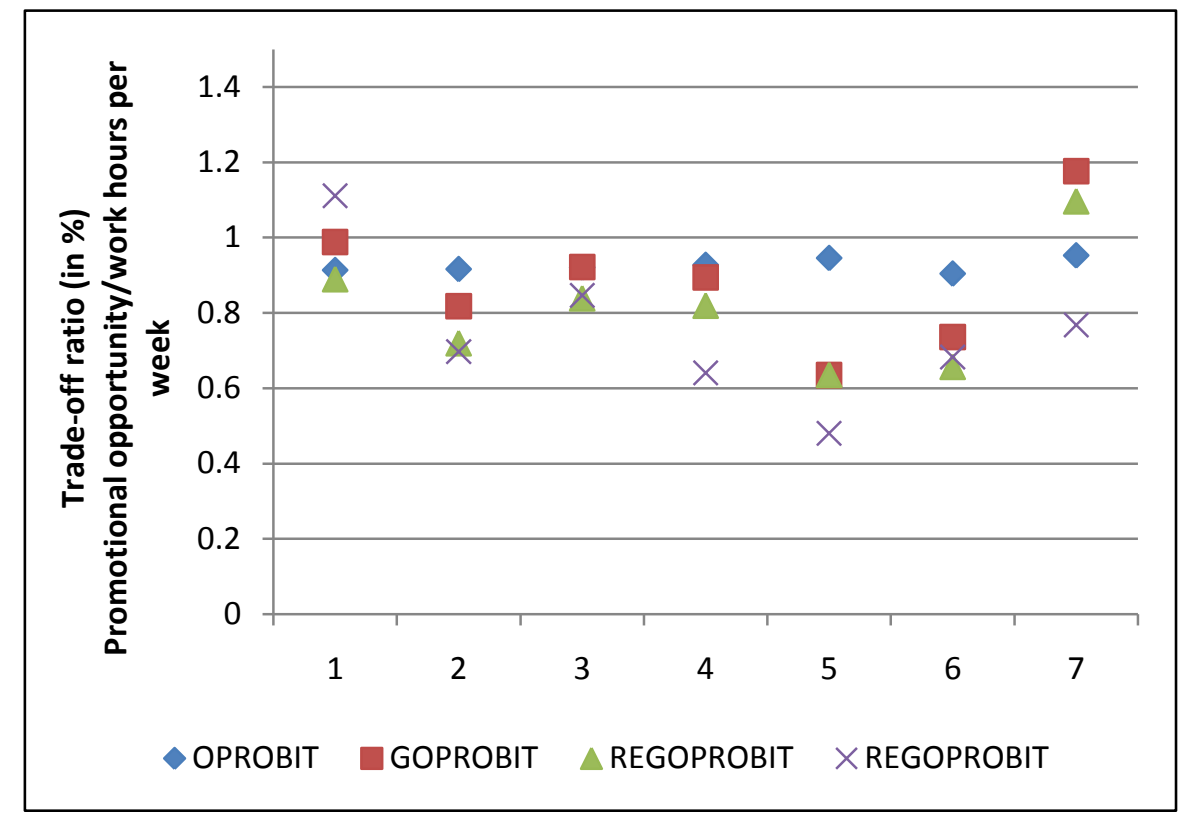

Figure 3C: How much work hours per week (in \%) has to be reduced to compensate having no promotional opportunity at the workplace? 
Table 1A: Descriptive Statistics

\begin{tabular}{lcc}
\hline Main variables & M & STD \\
\hline Job satisfaction & 5.340 & 1.310 \\
Log of real pay per month & 6.820 & 0.839 \\
Job tenure & 10.280 & 4.615 \\
Job tenure^2 & 126.998 & 67.718 \\
Job size: 10-49 people & 0.298 & 0.458 \\
Job size 2: 50-499 & 0.341 & 0.474 \\
Job size 3: 500+ & 0.132 & 0.339 \\
Pension scheme & 0.545 & 0.498 \\
Union member & 0.124 & 0.329 \\
Promotion opportunity & 0.441 & 0.497 \\
Permanent job & 0.939 & 0.239 \\
Commute: 16-30 minutes & 0.284 & 0.451 \\
Commute:31-60 minutes & 0.154 & 0.360 \\
Commute: $61-90$ minutes & 0.024 & 0.154 \\
Commute: $91+$ minutes & 0.008 & 0.008 \\
log of hours worked per week & 3.445 & 0.487 \\
Self-employed & 0.004 & 0.066 \\
\hline
\end{tabular}

Note: $\mathrm{N}=76,052$. 
Table 2A: Heckman selection model (Probit)

\begin{tabular}{|c|c|}
\hline Selection into private/self-employment & $\beta$ \\
\hline \multirow[t]{2}{*}{ Age } & $0.205^{* *}$ \\
\hline & [0.00361] \\
\hline \multirow[t]{2}{*}{ Age-squared/100 } & $-0.274 * *$ \\
\hline & [0.00435] \\
\hline \multirow[t]{2}{*}{ Health: Poor } & $0.563^{* *}$ \\
\hline & {$[0.0365]$} \\
\hline \multirow[t]{2}{*}{ Health: Fair } & $1.122 * *$ \\
\hline & {$[0.0387]$} \\
\hline \multirow[t]{2}{*}{ Health: Good } & $1.425^{* *}$ \\
\hline & {$[0.0390]$} \\
\hline \multirow[t]{2}{*}{ Health: Excellent } & $1.496 * *$ \\
\hline & {$[0.0399]$} \\
\hline \multirow[t]{2}{*}{ Completed high school } & $0.119 * *$ \\
\hline & {$[0.0188]$} \\
\hline \multirow[t]{2}{*}{ Completed university level } & $0.395^{* *}$ \\
\hline & [0.0193] \\
\hline \multirow[t]{2}{*}{ Ethnicity: Black Africans \& Caribbean } & $-0.146^{*}$ \\
\hline & {$[0.0725]$} \\
\hline \multirow[t]{2}{*}{ Ethnicity: Asians } & $-0.335 * *$ \\
\hline & {$[0.0578]$} \\
\hline \multirow[t]{2}{*}{ Ethnicity: Others } & $-0.232 *$ \\
\hline & [0.110] \\
\hline \multirow[t]{2}{*}{ Cohabiting } & 0.0303 \\
\hline & {$[0.0231]$} \\
\hline \multirow[t]{2}{*}{ Widowed } & $-0.135^{*}$ \\
\hline & {$[0.0574]$} \\
\hline \multirow[t]{2}{*}{ Divorced } & $-0.0986^{*}$ \\
\hline & [0.0393] \\
\hline \multirow[t]{2}{*}{ Separated } & $-0.0888^{*}$ \\
\hline & {$[0.0446]$} \\
\hline \multirow[t]{2}{*}{ Never married } & $-0.237 * *$ \\
\hline & {$[0.0335]$} \\
\hline \multirow[t]{2}{*}{ Men } & $0.611 * *$ \\
\hline & {$[0.0306]$} \\
\hline \multirow[t]{2}{*}{ Spouse pay: less than $£ 500 \mathrm{pm}$} & $0.299 * *$ \\
\hline & {$[0.0743]$} \\
\hline \multirow[t]{2}{*}{ Spouse pay: $£ 500-£ 999$ pm } & $0.197^{* *}$ \\
\hline & {$[0.0491]$} \\
\hline \multirow[t]{2}{*}{ Spouse pay: $f 1,000-f 1,499$ pm } & $0.246 * *$ \\
\hline & [0.0459] \\
\hline \multirow[t]{2}{*}{ Spouse pay: $f 1,500-f 1,999$ pm } & $0.112 *$ \\
\hline & {$[0.0470]$} \\
\hline Spouse pay: $f 2,000+p m$ & 0.00877 \\
\hline
\end{tabular}




\begin{tabular}{|c|c|}
\hline & {$[0.0480]$} \\
\hline \multirow[t]{2}{*}{ Men $x$ Spouse pay: less than $f 500$ pm } & 0.0576 \\
\hline & {$[0.0854]$} \\
\hline \multirow[t]{2}{*}{ Men x Spouse pay: $£ 500-£ 999$ pm } & $0.201 * *$ \\
\hline & {$[0.0691]$} \\
\hline \multirow[t]{2}{*}{ Men x Spouse pay: $£ 1,000-f 1,499$ pm } & $0.147^{*}$ \\
\hline & {$[0.0732]$} \\
\hline \multirow[t]{2}{*}{ Men x Spouse pay: $£ 1,500-f 1,999$ pm } & $0.156+$ \\
\hline & {$[0.0890]$} \\
\hline \multirow[t]{2}{*}{ Men $x$ Spouse pay: $f 2,000+p m$} & $0.225^{*}$ \\
\hline & [0.0940] \\
\hline \multirow[t]{2}{*}{ Spouse work hours: $16-29 \mathrm{hpw}$} & $0.148+$ \\
\hline & {$[0.0818]$} \\
\hline \multirow[t]{2}{*}{ Spouse work hours: $30-39 \mathrm{hpw}$} & $0.273^{* *}$ \\
\hline & [0.0443] \\
\hline \multirow[t]{2}{*}{ Spouse work hours: $40+\mathrm{hpw}$} & $0.270 * *$ \\
\hline & {$[0.0421]$} \\
\hline \multirow[t]{2}{*}{ Men x Spouse work hours: 16-29 hpw } & 0.0786 \\
\hline & {$[0.0936]$} \\
\hline \multirow[t]{2}{*}{ Men x Spouse work hours: $30-39$ hpw } & $-0.184 * *$ \\
\hline & [0.0667] \\
\hline \multirow[t]{2}{*}{ Men x Spouse work hours: $40+\mathrm{hpw}$} & $-0.148^{*}$ \\
\hline & {$[0.0755]$} \\
\hline \multirow[t]{2}{*}{ Rest of household's incomes } & $-0.0698 * *$ \\
\hline & {$[0.00517]$} \\
\hline \multirow[t]{2}{*}{ Number of children: Age $0-2$} & $-0.543 * *$ \\
\hline & [0.0159] \\
\hline \multirow[t]{2}{*}{ Number of children: Age 3-4 } & $-0.394 * *$ \\
\hline & [0.0153] \\
\hline \multirow[t]{2}{*}{ Number of children: Age 5-11 } & $-0.215^{* *}$ \\
\hline & [0.00939] \\
\hline \multirow[t]{2}{*}{ Number of children: Age 12-15 } & $-0.112 * *$ \\
\hline & {$[0.0111]$} \\
\hline \multirow[t]{2}{*}{ Number of children: Age $16-18$} & $-0.410 * *$ \\
\hline & [0.0145] \\
\hline \multirow[t]{2}{*}{ Shared ownership of household } & -0.0755 \\
\hline & {$[0.0776]$} \\
\hline \multirow[t]{2}{*}{ Rented household } & $-0.547 * *$ \\
\hline & [0.0169] \\
\hline \multirow[t]{2}{*}{ Rent free household } & $-0.153^{* *}$ \\
\hline & [0.0462] \\
\hline \multirow[t]{2}{*}{ Other kind of household ownership } & $-0.155+$ \\
\hline & {$[0.0846]$} \\
\hline Constant & $-4.218^{* *}$ \\
\hline
\end{tabular}

Note: $\mathrm{N}=194,107$. Robust standard errors are in parentheses. Additional controls include regional dummies (19) and wave dummies (18). 